\begin{abstract}
Title of Thesis:

LANGUAGE PHENOTYPING IN YOUNG CHILDREN WITH CONCUSSION

Melissa Dawn Stockbridge, Master of Arts, 2017

Thesis Directed By:

Professor Rochelle S. Newman, Ph. D., Department of Hearing and Speech Sciences
\end{abstract}

Mild traumatic brain injuries (mTBIs) are typically viewed as those that do not result in prolonged periods of unconsciousness. Concussions, or the mildest form of brain injury, are the most prevalent in young children. Presently no single framework or screening assessment measure exists for language in young children. In this study, children who had recently experienced a concussion were compared with children who had no history of head injury on a battery of linguistic and cognitive-linguistic tasks. Group differences in both lexical- and discourse-level skills were identified, as well as domain-general cognitive skills. Significant differences were noted in category identification, phonological working memory, grammaticality judgment, segregation and selective attention to spoken instructions in the presence of a distractor, visually recognizing spoken targets presented in a short story, and visual non-verbal problem solving, all with moderate effect sizes. This research will inform classroom and in-home accommodations to assist children during the period of recovery. 


\title{
LANGUAGE PHENOTYPING IN YOUNG CHILDREN WITH CONCUSSION
}

\author{
by \\ Melissa Dawn Stockbridge \\ Thesis submitted to the Faculty of the Graduate School of the \\ University of Maryland, College Park, in partial fulfillment \\ of the requirements for the degree of \\ Master of the Arts in \\ Speech-Language Pathology \\ 2017
}

Advisory Committee:

Professor Rochelle S. Newman, Ph. D. Chair

Professor Nan Bernstein-Ratner, Ph. D., CCC-SLP

Professor Jan Edwards, Ph. D.

Professor Philip Resnik, Ph. D.

Assistant Professor Alexander J. Shackman 
(C) Copyright by

Melissa Dawn Stockbridge 2017 


\section{Acknowledgements}

The author would like to acknowledge the support of Robert G. Graw, M.D., and Anthony Doran, Psy. D., from RightTime Medical Care and Head First Sports Injury and Concussion Care centers for supporting the recruitment necessary to conduct this research. I gratefully acknowledge Drs. Andrea Zukowski and Colin Phillips, of the Language Science Center at the University of Maryland, for providing indispensible contributions informing the development of this screening battery from the perspective of linguistics and language development, and Kristin Slawson, of the University of Maryland Hearing and Speech Clinic, for providing invaluable clinical insight into this population. I also would like to thank Dr. Kristin King for facilitating my first opportunities to conduct research in the population of people with recent concussion and Colleen Worthington for inspiring me to always consider the real-world benefits of our clinical research for patients' everyday lives. Finally, I would like to acknowledge the wonderful undergraduate research assistants who joined me in driving countless miles to and from urgent care centers and embracing the challenge of approaching and assessing young children with recent injuries in a healthcare environment over the past five years: Corrin Cromwell, Danielle Koontz, Sanuri Hennayake, Ryan Mortman, Hanieh Javaheri, Keren Rosario Ortiz, Mark Vogel, Chris Pellegrino, Gurleen Kaur, Arielle Kazlow, Bradley Hanson, Abbie Mathews, Arielle Kazlow, Courtney Romanowski, Samantha Wermers, and Paul Woloszyn. 


\section{Table of Contents}

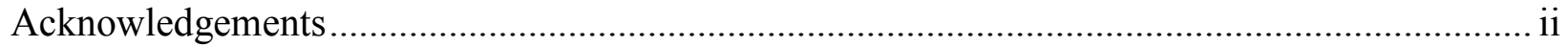

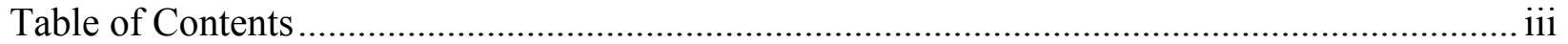

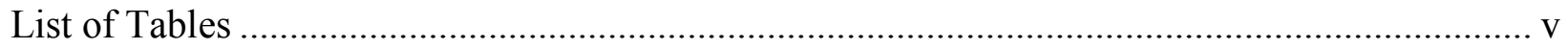

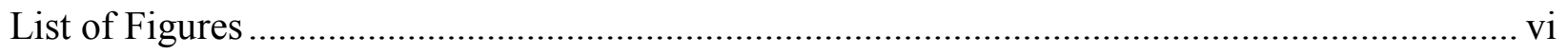

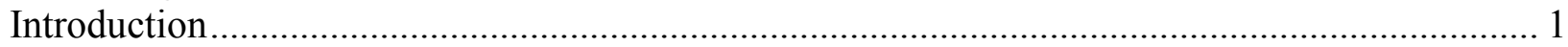

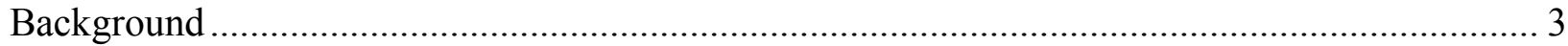

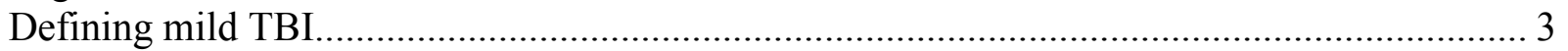

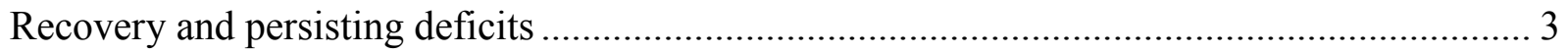

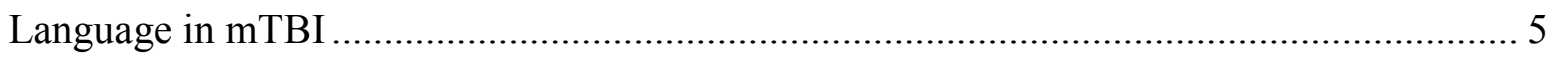

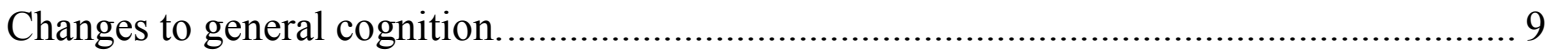

Multiple injury exposure and age: understanding a broad heterogeneous profile ............... 10

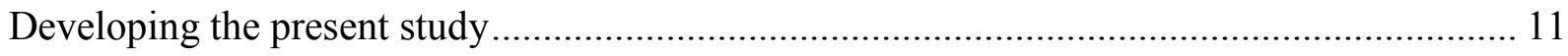

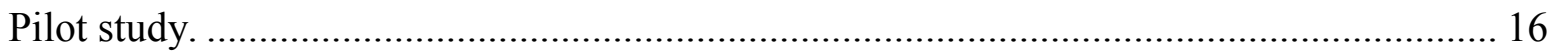

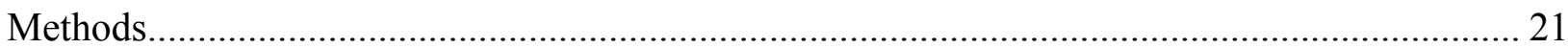

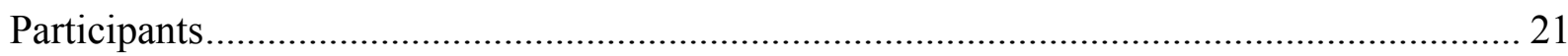

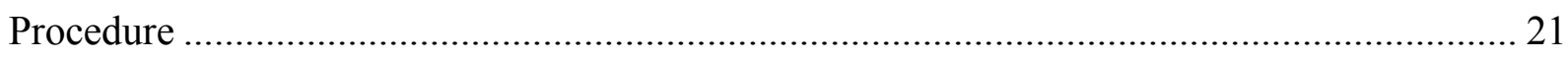

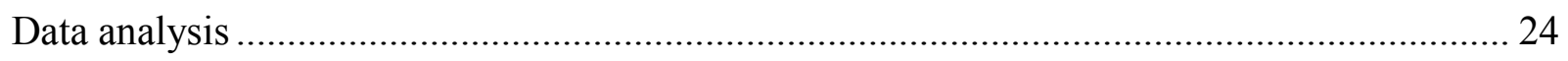

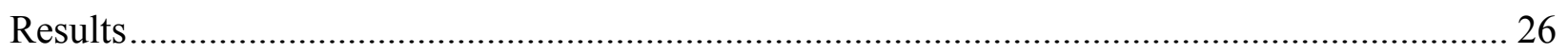

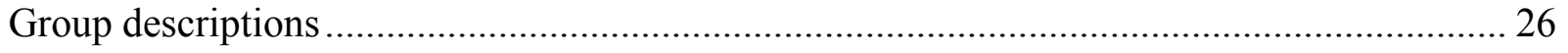

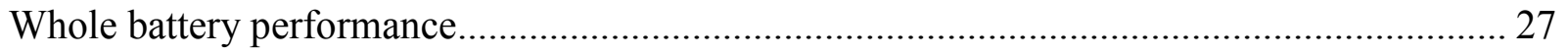

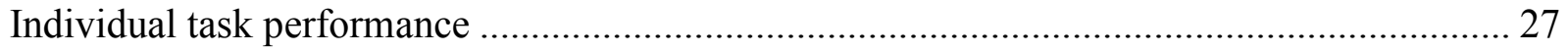

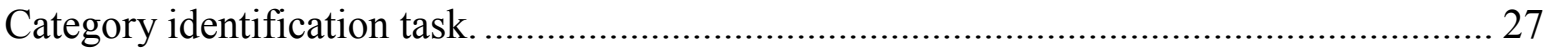

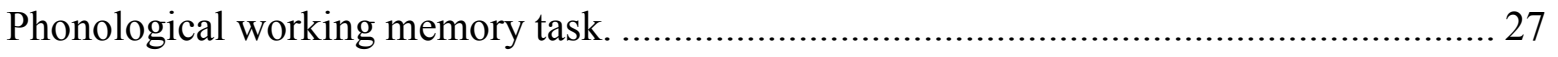

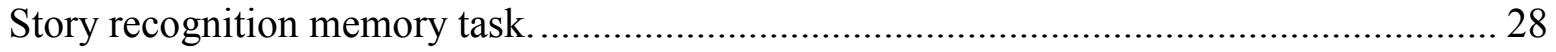

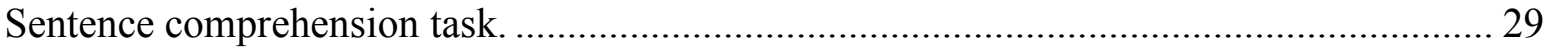

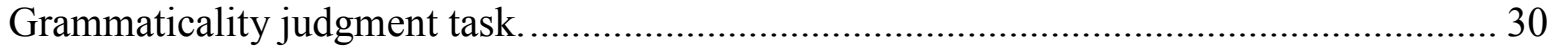

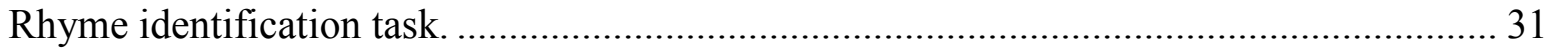

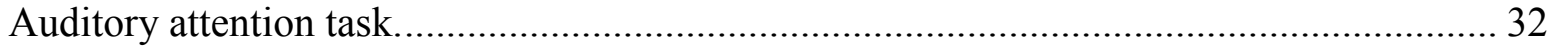

Raven's Coloured Progressive Matrices......................................................................... 33

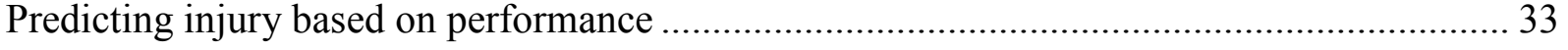

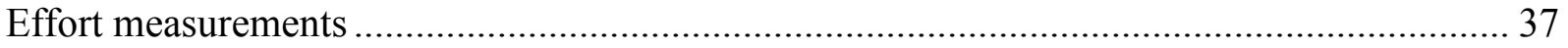

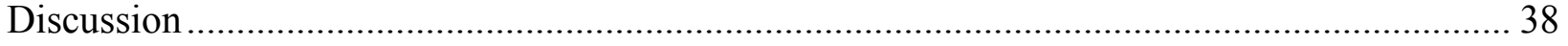

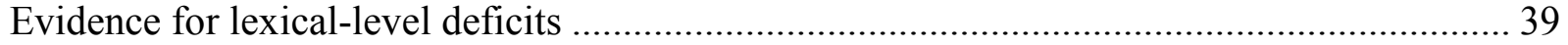

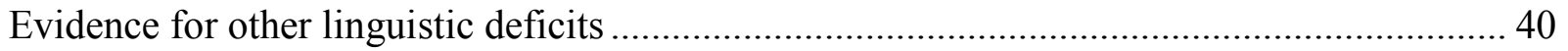

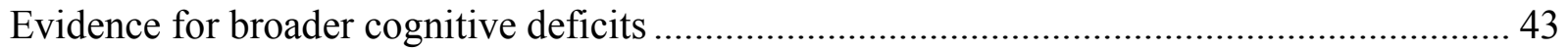

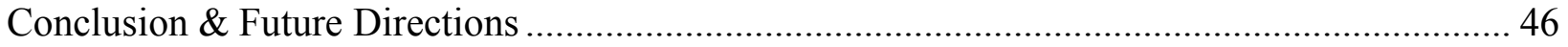


Appendix A: Sample Experimental Stimuli …………........................................................ 49

1. Rhyme identification task ......................................................................................... 49

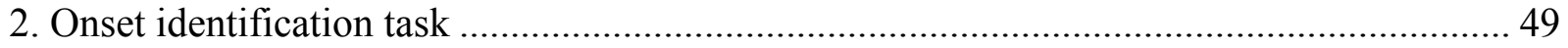

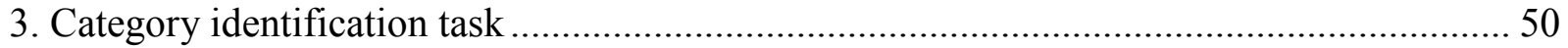

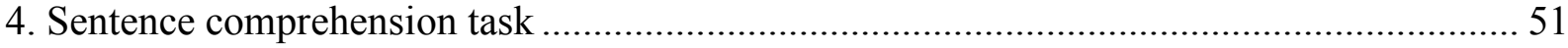

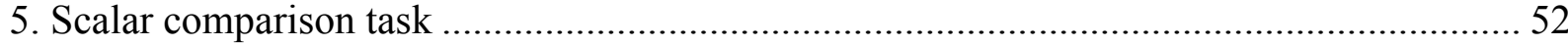

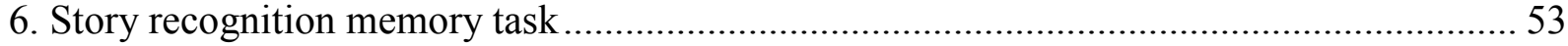

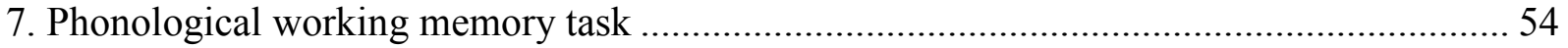

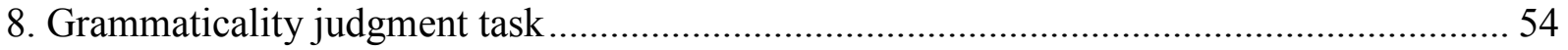

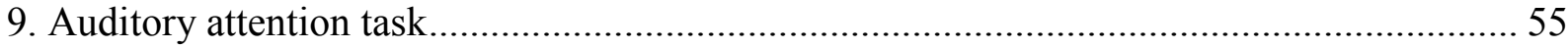

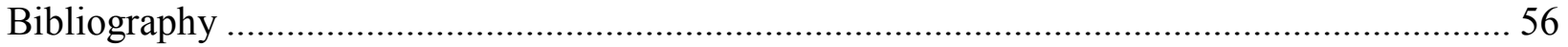




\section{List of Tables}

Table 1: Event characteristics of injured group

Table 2: Results summary

Table 3: Pearson correlation matrix

Table 4: Component matrix 


\section{List of Figures}

Figure 1: Pilot performances on each task by age

Figure 2: Story recognition memory item analysis

Figure 3: Correlation scatterplot matrix for selected tasks across groups

Figure 4: Factor analysis eigenvalues 


\section{Introduction}

Each year, over 150,000 sports- and recreation-related traumatic brain injuries (TBIs), including concussions, are treated in the United States in children under 19 years

old (Gilchrist, Thomas, Xu, McGuire, \& Coronado, 2011). Children and adolescents have an increased risk for traumatic brain injuries, and those injuries tend to have increased severity and prolonged recovery. Among children between 5 and 14 years old, mild injuries are the most prevalent (J. F. Kraus, Fife, Cox, Ramstein, \& Conroy, 1986). However, even a relatively minor traumatic brain injury (TBI) can result in adverse physical, cognitive, behavioral, educational, and social consequences (Beauchamp \& Anderson, 2010; Ponsford et al., 1999, 2001).

Presently, no single framework or screening assessment measure exists for language in young children following a mild head injury (Davis \& Purcell, 2014), despite observations of language difficulties occurring with single words and sentences in this population. Broader cognitive measures, which are most commonly used immediately following concussion in older children and adults, are being developed for use in this younger population. In young children, even mild deficits in language may have significant reverberations in education and development suggesting the need for better assessments of function. This work is an attempt to address the need for better screening assessment of language following concussion in young children. In the sections below, the population of mild injury will be identified more exactly, and then evidence for language deficits associated with mild injury across domains will be reviewed. Here, 5to 10 -year-old children with concussion injuries were recruited from local urgent care concussion centers to complete age-appropriate linguistic screening tasks for the purpose 
of determining which linguistic skills and capacities were associated with the greatest deficits following injury. To assess the sensitivity and specificity of the screening tasks, their results were compared to the performance of age-matched children without concussion. 


\section{Background}

\section{Defining mild TBI}

Mild traumatic brain injuries (mTBIs) are typically viewed as those that do not result in prolonged periods of unconsciousness. Mild TBIs are not expected to lead to gross chronic deficits in cognitive or physical performance, although they may lead to subtle transient deficits. These injuries have been defined using various criteria in the literature, but severity of injury typically is determined based on length of alteration of consciousness (30 minutes or less), lowest achieved Glasgow Coma Scale Score (13-15), Immediate Post-Concussion Assessment and Cognitive Testing (ImPACT) performance, Acute Concussion Evaluation (ACE), and sub-cortical evaluation examining changes to cranial nerves, ocular-motor functioning, and balance functioning.

\section{Recovery and persisting deficits}

Cognitive and behavioral symptoms caused by an mTBI in children and adults dissipate within weeks or months, and it is thought that people with these injuries typically recover all function on cognitive assessments for concussion (Asarnow et al., 1995; Carroll et al., 2004; Ponsford et al., 1999, 2001). However, every child does not experience this pattern of recovery in the same way. While many children appear essentially unchanged after a TBI, others experience diverse, prolonged deficits and extreme distress (Collins, Lovell, Iverson, Ide, \& Maroon, 2006; Field, Collins, Lovell, \& Maroon, 2003; Guskiewicz \& McLeod, 2011). Persistent symptoms or impairments are most common among children who have had prior head injuries, pre-existing learning difficulties, neurological or psychiatric problems, or family stressors (Ponsford et al., 1999). In a recent meta-analysis of outcomes of brain injury in children and adolescents, 
Lloyd and colleagues found $6.8 \%$ of reviewed studies indicated adverse academic outcomes, $17.8 \%$ of reviewed studies indicated adverse neuropsychological outcomes, and $48.9 \%$ of reviewed studies indicated adverse psychosocial outcomes following mTBI (Lloyd, Wilson, Tenovuo, \& Saarijärvi, 2015). It also has been observed that adults who experience repeated closed head injuries over time, such as professional boxers and football players, may develop severe and permanent cognitive deficits. This cumulative effect of multiple smaller injuries is termed "chronic traumatic encephalopathy" (McKee et al., 2009; Uryu et al., 2002). The observations that most children appear to recover fully, but repeated injuries lead to gross chronic deficits, appear to conflict. How can a person completely recover from each injury, yet still experience a severe deficit after multiple injuries?

One potential explanation is that the available and widely used tools for assessment are not sufficiently sensitive, either because of their level of difficulty or because of the performance variables measured, to capture gradual cognitive changes from mild injuries that aggregate over time. Even as accuracy appears to return to "normal," the cognitive process may be less efficient than before the injury (Asarnow, Satz, Light, Lewis, \& Neumann, 1991; Boll, 1983). In such cases, the individual requires a greater amount of processing time before responding to a cognitive or linguistic task, such as naming or describing an object (Stockbridge, Doran, King \& Newman, under review). Further, as most assessments of cognition following brain injury are designed for adults, there is relatively little in the assessment of pediatric patients that appreciates the role of the injury relative to their cognitive and linguistic development and environment (e.g., age at injury, premorbid status, and family resources; Babikian \& Asarnow, 2009). 
Whereas an injury in an adult will primarily impact processing of previously acquired information, an injury in a child has the potential to disrupt learning and developmental processes, leading to less straightforward deficits that may last a lifetime. Five- to tenyear-old children typically are assessed using neurocognitive measures designed for assessment into young adulthood. However, the five- to ten-year-old age range specifically captures the start of formal education and, relatedly, greater functional utilization of language and metacognitive skills (Babikian \& Asarnow, 2009). Language is one domain in which a deficit can have particularly far-reaching ramifications. By 10 years old, the focus of education transitions from teaching basic language skills (speaking, reading, and writing) to leveraging those skills to teach novel concepts (Chall, 1983). If a TBI has caused a child to experience language deficits, then this can profoundly disrupt the child's academic success. A better understanding of the linguistic changes and the trajectory of recovery in young patients can inform prognosis and can lead to improved assessment of performance and rehabilitative interventions.

\section{Language in mTBI}

Changes in language performance by children with brain injuries have been noted in various linguistic skills, and these can have a profound impact on the child's education and social growth. Anomia, difficulty naming objects or people that are perceived correctly (essentially, severe "tip-of-the-tongue" experiences), is the most common reported disturbance (Ylvisaker, 1986). Children with brain injuries appear to have more difficulty producing language for communication rather than understanding language used by others. Previous research has observed specific effects of mTBI on language ability in children and adolescents across various domains, from single words (Barnes, 
Dennis, \& Wilkinson, 1999; Ewing-Cobbs, Levin, Eisenberg, \& Fletcher, 1987;

Wrightson, McGinn, \& Gronwall, 1995) to sentences (Ewing-Cobbs \& Barnes, 2002;

Ewing-Cobbs et al., 1987), discourse (Biddle, McCabe, \& Bliss, 1996; Dennis \& Barnes, 1990; Jordan, Murdoch, \& Buttsworth, 1991), social skills, and pragmatics (Dennis \& Barnes, 1990, 2000; Sacco et al., 2008). However, many of these studies were conducted examining a single language capacity, rather than more broadly phenotyping the language abilities of a given injured child. Also, many prior studies only contained a small subset of children with mTBI within an experimental group containing children with brain injuries of greater severity. These children more recently may be labeled as having a "mild complicated injury," which is less common in the general population than concussion. Concussion specifically refers to an injury of the least severity but highest prevalence within the mild brain injury definition. It is the hope that the tasks identified in this research will be informative in more comprehensively assessing young children with concussion as they heal after injury and will provide a better understanding of chronic effects of concussion on language development in this population.

\section{Changes at the word level.}

Children with early injuries (i.e., before 8 years old) have demonstrated more consistent impairment in lexical level skills than do children with similar injuries that occurred at an older age (Ewing-Cobbs \& Barnes, 2002; Shaffer, Bijur, Oliver, \& Rutter, 1980), even when the injuries were relatively mild (Wrightson et al., 1995). For example, children with recent brain injuries have impaired accuracy and increased reaction time (i.e., disfluency) when decoding words and pronounceable non-words, with significantly lower performance when injuries occurred at younger ages (Barnes et al., 
1999). The effect of injury on reaction time is greater for real words compared with nonwords, and it varies by the type of word, with words using uncommon orthographic or phonetic characteristics (e.g., "ache") associated with the greatest deficit. This suggests that difficulties in these tasks may arise due to underlying deficits in accessing stored information, as these irregular and or uncommon forms cannot be "sounded out" based on spelling alone. Also, children with brain injuries demonstrate impaired ability to name and describe objects and people and to list words that have a common theme (e.g., all types of food or all words that begin with the letter "f"; Ewing-Cobbs et al., 1987), also suggesting underlying difficulty accessing stored word representations. Taken together, observations of phonetic and semantic access deficits support the notion that difficulties in access are not specific to a single type of information, but perhaps exist more generally.

\section{Changes at the sentence and discourse level.}

Children with brain injury also demonstrate impaired performance at the sentence and discourse levels, when repeating sentences aloud and writing sentences, whether in response to dictation or when telling stories (Ewing-Cobbs \& Barnes, 2002; EwingCobbs et al., 1987). Furthermore, they demonstrate decreased overall expressive language and production of narratives (Biddle et al., 1996). Biddle et al. (1996) observed the frequent use of strategies such as repetitions, fillers, and false starts, potentially suggesting difficulties with word retrieval.

Narrative language, or telling stories and recounting events, requires not only efficient, intelligible use of language, but also the integration of an organizational structure that allows the listener to follow what is being said. Specific deficits in narrative 
language have been observed in children with mTBI. These children tend to include fewer essential story components (e.g., setting, action) and fewer transitions (e.g., first, then, next, later). They also include fewer overall utterances and words, as well as having less variety in the words they do use (that is, a decreased type-token ratio, suggesting that they repeat or reuse the same words rather than generating novel words to decrease the repetitiveness of their language). There is conflicting evidence regarding children with head injuries' performance in overall information flow (Dennis \& Barnes, 1990), total number of propositions in a narrative, and story grammar (Jordan et al., 1991). However, an increased use of ambiguous referents (e.g., saying, "then they went to the party" without previously identifying who "they" are) and omissions of essential information (Biddle et al., 1996; Chapman et al., 1992; Ewing-Cobbs, Brookshire, Scott, \& Fletcher, 1998) consistently have been noted. Many of these changes are what might be expected given the difficulties accessing information at the word-level, as discussed above. However, it is unclear whether additional problems are specific to the sentence level as this is not frequently examined. When a child with brain injury attempts to convey information about an event or give an explanation, these deficits in the way the child communicates make it more difficult for him or her to be understood. Thus, the invested listener will have to engage in more effortful strategies (e.g., asking for clarification, filling in the "blanks" themselves) to follow along with what the child is saying. This shift in the burden of understanding (i.e., increased listener burden ratio) means that the child will have more difficulty communicating effectively in general, with considerable difficulty expressing themselves in situations where the listener cannot engage in ongoing strategies to assist in reaching understanding, as in academic assessments. 


\section{Changes to general cognition.}

While a broad review of changes to overall cognition in pediatric head trauma is beyond the scope of this thesis, several potentially relevant findings bear upon the interpretation of observed language deficits. Apparently domain-specific language deficits could reflect broader cognitive differences, such as difficulties in working memory, executive function, or core cognitive capacity (Borgaro, Prigatano, Kwasnica, \& Rexer, 2003; Ewing-Cobbs et al., 1998), typically found in this population. Children with early injuries perform more poorly on standardized tests of general intelligence than children who are older at the time of their injury (Anderson \& Moore, 1995) even beyond the acute phase of recovery, and younger children do not demonstrate the same trajectory of intelligence quotient score over the course of recovery as children who are older at the time of their injuries. This may reflect the impact of injury on their process of maturation and learning. Deficits in speed of processing in children with head injury have been observed consistently and across domains, perhaps implicating deficits in several aspects of information processing (Barnes et al., 1999; Haut, Petros, Frank, \& Haut, 1991; Tromp \& Mulder, 1991).

Despite these deficits, there appear to be some skills more robust to brain injury in the developing mind than others. For example, children with brain injury typically demonstrate relatively well-preserved representation of mental states and performance on false belief tasks (Snodgrass \& Knott, 2006; Turkstra, Dixon, \& Baker, 2004; Walz, Yeates, Taylor, Stancin, \& Wade, 2009). A meta-analysis of case-control studies in children show negligible differences in full-scale intelligence, performance intelligence, working memory, problem solving, visual immediate memory, and visual perceptual 
functioning between healthy subjects and those with mTBI (Babikian \& Asarnow, 2009). This is in contrast to effects on verbal intelligence, verbal immediate and delayed memory, and attention deficits that were noted when the experimental group was considered up to two years after injury. With these exceptions, the majority of skills and capacities examined were not affected (or minimally affected), and recovered by two years post-injury (Babikian \& Asarnow, 2009; Bijur, Haslum, \& Golding, 1990; Satz, Zaucha, McCleary, \& Light, 1997).

\section{Multiple injury exposure and age: understanding a broad heterogeneous}

\section{profile}

If a child receives multiple mild head traumas over the course of childhood, each one recovering spontaneously, the impact of such an aggregated effect of multiple injuries may only be realized by comparing the efficiency of cognitive processes before and after each insult as the child grows older. However, it is difficult to distill from the existing pediatric literature a clear picture of the relationship between cognitive deficits and age. This may in part be due to the differences across studies in how groups of younger and older children are operationally defined. Among studies of cognitive effects of head injuries in children, the distinction between young and older patients appears to divide outcomes at varying points between 5 and 10 years old. For example, older children are defined as 6 years old (Barnes et al., 1999; Kriel, Krach, \& Panser, 1989), 7 years old (Anderson \& Moore, 1995), 8 years old (Shaffer et al., 1980), or 9 years old (Barnes et al., 1999). What is clear is that currently there is no standardized assessment for children under 10 years old, and a child's first cognitive testing may not occur until the child is at least this age and participating in school sports. By that time, the child 
already may have suffered one or more un-assessed concussions. The aggregated effect of mild brain injuries in early life may contribute to the heterogeneity of performance observed among pre-season, "pre-injury" adolescents, and highlights the need to examine language performance in younger populations. This is further supported by the observation that competitive contact sports have become more common in younger and younger children (Merkel, 2013).

\section{Developing the present study}

Children with mTBIs have demonstrated deficits overall in expressive language (Bonnier, Marique, Van Hout, \& Potelle, 2007) and receptive language (Barnes et al., 1999). Specific language skills affected include naming and describing objects or images, listing words within a given thematic category (Ewing-Cobbs et al., 1987), decoding words and non-words (Barnes et al., 1999), repeating sentences aloud or writing sentences in a story (Biddle et al., 1996; Ewing-Cobbs \& Barnes, 2002; Ewing-Cobbs et al., 1987), and utilizing pragmatic skills (Dennis \& Barnes, 2000). Deficits in language performance have been considered both in terms of accuracy and in terms of reaction time. Further, children in this population have demonstrated deficits in auditory selective attention (Bonnier et al., 2007). Broader neurocognitive deficits have been found in some studies; however, meta-analysis of these effects has shown inconsistent findings (Babikian \& Asarnow, 2009). These observations suggest that language skills in particular may be affected by concussion, relative to other types of cognitive skills. If so, a screening measure for linguistic skills may be beneficial for use in this population. No previous study has attempted to identify broad language deficits, within the same sample of children with concussion, using an efficient screening measure. This gap in the 
literature makes it difficult to identify relative areas of weakness in this population or to qualify relative performance within a given individual. Thus, the goal of the current proposal is to examine success on a wide range of brief linguistic tasks in young children to gain a better understanding for how these skills are affected, with the ultimate goal of developing standards for interpreting performance following concussion.

While designing the present study in light of what is known about language in children with brain injury, a few key factors were taken into consideration. First, the planned measure would need to have simple responses that could be easily scored. Whereas the majority of existing findings regarding language deficits in this population addressed production, having a child produce language would require a kind of nuanced analysis that is difficult to automate and standardize. Language sample analysis has remained the gold standard for language assessment, and efforts toward automated or computer-assisted language sample analysis (e.g., CHAT, SALT) have seen considerable development and refinement over time(MacWhinney, 1991; Miller \& Chapman, 1985). Despite these advances, and for reasons not entirely clear, these automated methods of language assessment are rarely employed by practicing speech-language pathologists in the typical course of assessment. Anecdotally, efforts to promulgate the use of even very straightforward language computational tools, such as those used in Child Language Data Exchange System (CHILDES), have resulted in very slow adoption into clinical practice(MacWhinney, 1991). Therefore, tasks were chosen that would necessitate a latent lexical access, such that the child would have to access the word or words to answer correctly, but would not actually have to produce the word or words as the response. 
Second, tasks were chosen to address specific questions left by apparent gaps in the existing literature. Prior studies have found that individuals with brain injury have difficulty naming common objects, decoding words, and pronouncing non-words. However, it is unclear what aspect of the process of naming, such as visual feature processing, access to the phonological input or output lexicon (needed for determining and producing the sound of the word itself), or access to the semantic system (where word meanings are stored and accessed) results in the deficit. Considering these observations, a rhyme identification task and a word onset identification task were designed and included in the language battery. In the rhyme identification task, participants see three images on the screen, each with a common name (e.g., a picture of a bee, a knee, and a horse; see Appendix A1). Participants then were asked to identify which image of the three was the odd-item-out that did not rhyme. In the case of this example, the child would have to recognize that the first picture was of a "bee," the second was of a "knee," and the third was of a "horse," and that, of these words, "horse" did not rhyme. Thus, the horse would be the correct response to this item; but more importantly, arriving at that conclusion required accessing word forms of three frequently used words. A similar, but simpler task, was the word onset identification task. This task followed the same basic format as the rhyme task. While it still required children to have phonetic awareness, it did not require a young child to understand the concept of rhyme (e.g., "game," "girl," and "house"; see Appendix A2).

Although accessing and comparing known, familiar word forms is informative, there are additional underlying skills thought to be important for many language abilities, such as phonological working memory. With this in mind, a task was included in which 
participants compared non-word syllable strings heard in succession by two different speakers (e.g., "Ba-See-Da" and "Ba-Kee-Da") and then were asked to determine whether they were the same string or whether they were different. Strings began relatively short, with three syllables each, but became progressively longer over the course of the task, up to eight syllables in length. As with the skill examined in the rhyme and onset identification tasks, phonological memory tasks also are typically measured via production. However, in this case, participants selected either a smiling face or a frowning face to identify whether the two strings were the same or different, respectively. Another underlying skill necessary for language is identifying and understanding the relationships between concepts. Evidence of deficits in access to semantic word information has been noted in children with head injury as they demonstrate difficulty naming members of a common category or those sharing a common feature. Semantic features within stored representations also are important to correctly naming pictures, another deficit observed in this population. Rather than having participants name members of a category, three images were presented on the screen that either shared a common theme or category (e.g., vehicles, fruits, insects, items of clothing; see Appendix A3) or did not. To respond correctly, participants had to identify whether a common category was being represented, what that category was, and whether each item fell within it. As with the previously described tasks, these images did require a kind of latent access, but unlike the rhyming and onset task, a correct response here required latent access to semantic information.

Third, tasks were developed that spanned levels of linguistic complexity, from single words to grammatical constructions and from small stimuli to longer verbal tasks. 
These tasks inform the interpretation of deficits seen in discourse and expressive language. It is important to distinguish whether deficits observed in complex language tasks purely are the result of lexical-level difficulties compounded at a larger scale or whether skill competencies in grammatical structure (i.e., syntax) play a role in the deficits observed. To examine this contrast, a sentence comprehension task was included, in which the participant was shown three images of a scene and had to interpret a sentence correctly to identify the scene described in the sentence. Sentences that were used required the participant to interpret prepositional phrases and clausal structures correctly to select the correct response (see Appendix A4). To further contribute to understanding the contrasting theories of this language deficit, children with a recent concussion were asked to identify whether a syntactic error had occurred in a sentence. In particular, the errors focused on verb agreement or other relationships between words (e.g., beginning a sentence about a woman, Mary, and then using feminine pronouns consistently throughout when referring back to her). Participants were asked to listen to a sentence and then determine whether the sentence as a whole was grammatically correct. In response to anecdotal observations reported by clinicians working with brain injured individuals more generally, another comprehension task was included that also probed understanding at the sentence level, specifically examining the use of abstract vocabulary used to contrast two samples on a scale (e.g., bigger, smaller, taller, shorter, longer). This task provided additional information to assist in understanding sentence-level differences, both because the use of this particular kind of abstract vocabulary requires a comparative relativity, wherein being "bigger" is only true or false relative to a comparison, and because word order in English sentences is paramount to the correct interpretation (i.e., 
"Is the worm shorter than the rope?" has an opposite response from "Is the rope shorter than the worm?"; see Appendix A5).

Finally, a verbal memory task was included to better characterize the previously reported memory deficits in the context of spoken language. In this task, children heard a story and had to remember a series of key words. To simplify this task considerably, the story itself was very brief (42 seconds) and contained simple, short sentences with a theme familiar to the target age group (getting ready for school). Within the story, as it was told, the speaker flagged a key target word within each sentence (e.g., "It was my cat. Remember 'cat."'). These target words were content words relevant to the story as a whole and thought to be reasonably salient for the listener. Importantly, this task did not require participants to generate anything related to the story directly; instead, after the story was read, for each previously identified target word, participants were asked to examine two images and select the one that had occurred as a key word (e.g., a picture of a cat and a dog; see Appendix A6). This made this task an assessment of recognition, a far lower threshold of remembering than recalling a story or a target without any manner of prompt. Taken together, this battery of novel tasks was developed for the purpose of this research and designed to provide nuanced but important information for better understanding the previously established findings of deficits in language in children with concussion.

\section{Pilot study.}

To narrow down age-appropriateness (both in terms of developmental progression of skills and in terms of administration of tasks), a pilot study was conducted in typical children within the target age range. For the pilot study, 72 healthy children, aged 4 years 
6 months to 9 years 11 months, were assessed using the diverse collection of eight language tasks described above. The tasks were intended to tap both receptive language and passive expressive language/language access without explicit production. The omission of explicit language production was important to make later computerized assessment of performance both automatic and objective. The tasks were intentionally diverse, focusing both on domains of language reflected in the literature and on critical emerging language skills for children in the selected age range.

\section{Methods.}

The items and tasks were developed to facilitate a brief, but effective, novel measure tailored to what is known about the population of young children with concussion. As described above, the tasks included: identifying rhymed pairs, identifying pairs with identical phonemic onset, sentence comprehension, category membership, scalar comparison, phonological working memory, story memory, and grammaticality judgment (see Appendix A).

Each task was presented using Microsoft PowerPoint with an examiner present to record the child's responses. Each child's set of tasks was balanced across the domains, ran approximately 10 minutes and varied across participants, such that no child received every task. Children were permitted to discontinue testing at any time.

\section{Results.}

A planned mid-collection examination of the data resulted in the scalar comparison task being removed from the testing because of clear observed ceiling effects. 
Overall task performances rapidly reached high levels of accuracy across the age range $(M=0.87, S D=0.34)$, with accuracy increasing by age from $4(M=0.68 ; S D=$ $0.48)$ to $10(M=0.94, S D=0.25)$, as anticipated (See Figure 1). As each child only completed a subset of all tasks, some tasks only were completed by a relatively small number of children. This led to limitations in the interpretation of those tasks. In the rhyme task $(M=0.79, S D=0.41)$, performance was consistently high and reached nearceiling levels for 8 - to 10 -year-old participants. In the onset identification task $(M=0.74$, $S D=0.44)$, performance was more varied, with 4-year-old children demonstrating poor

Figure 1: Pilot performances on each task by age

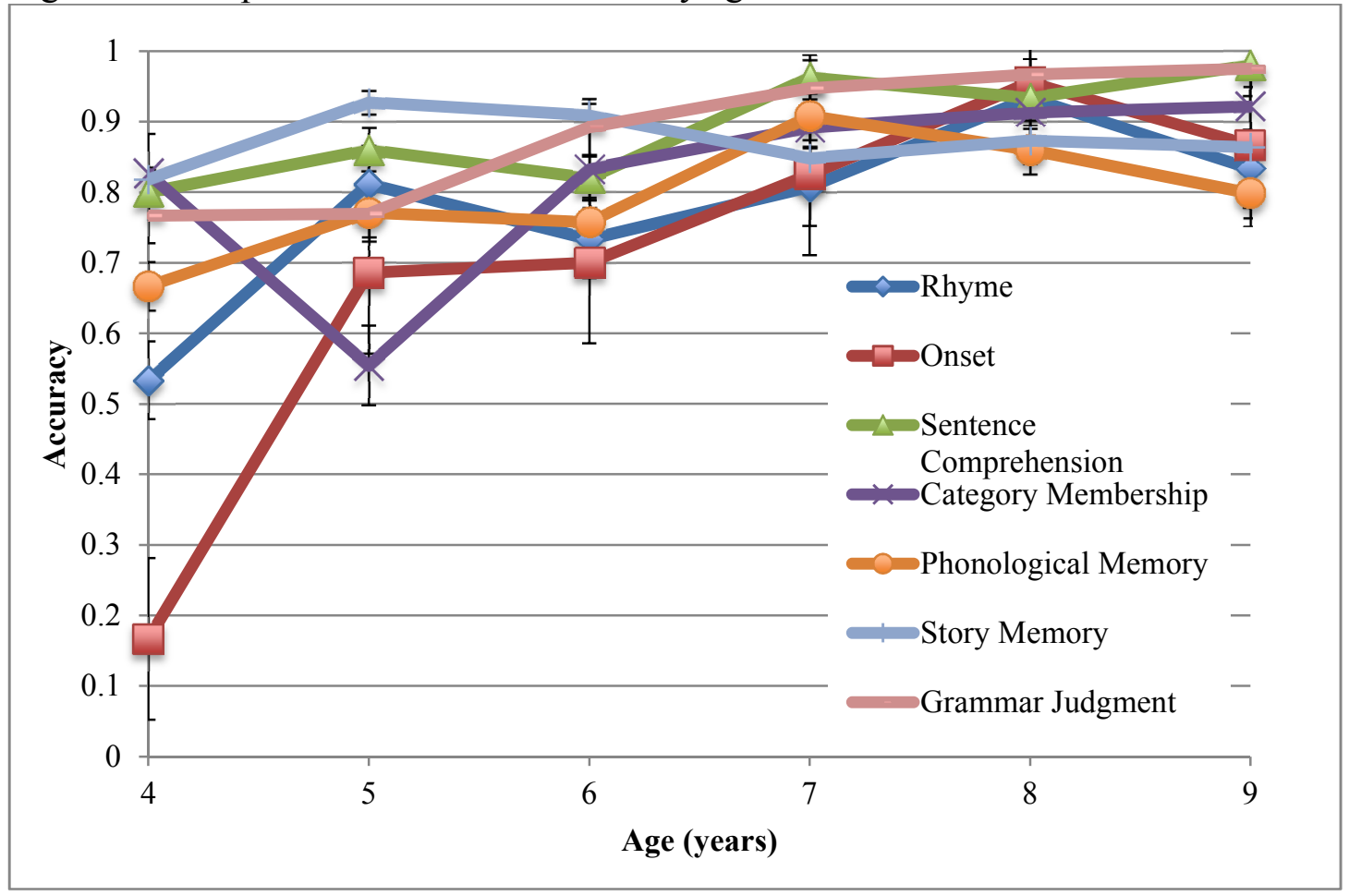

performance $(M=0.17, S D=0.38)$ and children 5 and over improving markedly. In the sentence comprehension task $(M=0.91, S D=0.29)$ children demonstrated a consistently high performance approaching ceiling levels from 7 to 10 years of age. In the phonological working memory task $(M=0.81, S D=0.39)$, children performed 
increasingly well with age from $4(M=0.67, S D=0.48)$ to $10(M=0.80, S D=0.40)$. Moreover, performance decreased as syllable length increased (3: $M=0.93 ; 4: M=0.82$; 5: $M=0.79 ; 6: M=0.72)$. This trend was consistent within each age group. In the story memory task $(M=0.89, S D=0.31)$, children performed consistently well, with a notable absence of consistent age effects. Finally, in the grammaticality judgment task ( $M=0.90$, $S D=0.30)$, performance increased with age from $4(M=0.77, S D=0.42)$ to near ceiling from ages $7(M=0.95, S D=0.22)$ to $10(M=0.98, S D=0.16)$.

\section{Discussion and interpretation for designing the current study.}

Tasks appropriate for assessing patients with concussion in the 5- to 10-year-old age range should be relatively well performed in healthy age-matched children, but not so easy as to produce a ceiling effect. Thus, it was determined that ideal tasks would have an average accuracy higher than $80 \%$, but no higher than $90 \%$. If the tasks are performed too poorly by healthy children, they may make injury more difficult to distinguish, or may represent situations where the child does not understand the underlying concept or instructions. The rhyme, category membership, and story memory tasks produced results that fit the criteria for an ideal task, falling between $80 \%$ and $90 \%$ in accuracy. In the category membership task, there was poor performance in the youngest children. However, this was based only upon the performances of 4 children; thus, this low average may be an artifact. The phonological working memory task fit these criteria for older children ages 7-10 $(M=0.86)$. The grammaticality judgment task $(M=0.81)$ and sentence comprehension $(M=0.83)$ task both fit these criteria for children between the ages of 4 and 6 . The differences observed in younger and older children within the group suggested that subsets of tasks perhaps should be grouped for sub-groups within the 
overall 4-10 yaer old age range. While the onset task also followed this trend, it did not reach the desired level of overall accuracy, and it was excluded from further analysis because of its similarity with the rhyme task and concerns about explaining the underlying concept to younger children (a potential explanation of the very low performance in the 4-6-year-old range, $M=0.52$ ).

Based on these observations, tasks were chosen to examine further in a small sample of children with concussion. Items in the grammaticality judgment task were truncated to include 20 of the original 60 pilot items in the interest of overall assessment time and participant fatigue. These 20 sentences represent conditions examining double auxiliaries (“Are Amanda and Tom are going to the store?"), verb agreement ("Peter and Sarah is ready to paint."), tag question pronoun and noun agreement ("The little boy fell down, didn't it?”), and tag question auxiliary agreement (“John is very tall, doesn't he?”). The phonological working memory task was expanded to include items of 7- and 8syllable length to gain a richer understanding of the effects of the injury on the memory of older children. It was predicted that significant accuracy and latency differences would be observed in children with concussion, informing a sensitive measure to distinguish deficits due to concussion. 


\section{Methods}

\section{Participants}

Thirty-two participants were recruited through the RightTime Medical Care urgent care and HeadFirst concussion management and referral centers. Healthcare professionals identified potential participants diagnosed with concussion through examination, including the Acute Concussion Evaluation (ACE) and the Immediate PostConcussion Assessment and Cognitive Testing (ImPACT). In addition, criteria used to diagnose concussion (rather than more severe injury) included having duration of unconsciousness no longer than 30 minutes and duration of post-traumatic amnesia no more than 24 hours. Participants were between the ages of 4 years; 11 months and 10 years; 11 months and were excluded for pre-existing developmental disabilities, speech, language, psychological, or neurological diagnoses, and prior head injury. They also were excluded if they received speech or language services in school. Children were native, monolingual speakers of English. Participants in this study were within the first month post-injury (no more than 30 days); although symptoms may persist beyond this point, we wanted to ensure that the participants in this study had not fully recovered from the injury. In addition, forty-one children made up the control group, matched at the group level on chronological age.

\section{Procedure}

Stimuli were presented using E-Prime experimental stimulus software, such that participants responded with a keyboard on a computer instead of a gesture toward the screen. This was designed to eliminate the need for proctor scoring in real time and provided for increased reliability in accuracy measures, as well as the opportunity for 
sensitive measures of response time. Task items were the same as those presented in the pilot testing, with the exception of an extended series of items within the phonological working memory task and changes to the grammaticality judgment task described above. All tasks were administered to all participants. Time limits were put in place for responding to easier tasks, to facilitate an efficient pace: 5 seconds to respond to each story recognition trial following the story and 10 seconds to respond to each rhyming judgment and category identification trial. All other tasks had an open-ended time limit, although response times were measured for all tasks. Task and task item order were randomized for all tasks except the story recognition memory task, in which trial items were presented in the same order as the targets in the initial story. All instructions were presented on the screen in text and read aloud simultaneously through an audio recording. All linguistic stimuli (e.g., sentences in the sentence comprehension task) were presented through an audio recording. Participants also reported a measure of effort on a scale from 1 ("Very easy") to 5 ('Extremely hard") for each task completed. Each testing session occurred in a private, closed area, free of visual and aural distraction.

In addition to the language tasks described above, some additional tasks were included for participants of all ages to augment the interpretation of the results of the experimental linguistic tasks. Prior research has identified deficits in auditory attention (Bernstein, 2002; Blanchet, Paradis-Giroux, Pépin, \& Mckerral, 2009) and processing (Bergemalm \& Lyxell, 2005; Cockrell \& Gregory, 1992) as consistent aspects of the diffuse brain injury chronic profile, even in the case of mild injuries (Bernstein, 2002; Blanchet et al., 2009; Musiek, Baran, \& Shinn, 2004; Turgeon, Champoux, Lepore, Leclerc, \& Ellemberg, 2011; Vander Werff \& Rieger, 2017). Recently, it even has been 
suggested that poor processing of fundamental frequency, important to listening in noise, may be a biomarker for concussion observable in children (N. Kraus et al., 2017; N. Kraus et al., 2016). To examine the impact of these deficits on linguistic tasks in the present study, an auditory attention task, a simplified coordinate response measure (CRM) task, was included to examine performance in selective auditory attention (Brungart, 2001; Brungart, Simpson, Ericson, \& Scott, 2001). Participants heard directions produced in two different voices presented simultaneously through headphones, those "for the Tiger" and those "for the Eagle," and were asked to attend selectively to one of the two sets of directions to select the correct response. Children responded by selecting one of four possible options for the Tiger's target location presented visually on the screen. Among the auditory attention trials, contrasting instructions could share a target number ("Ready Tiger go to blue seven now."/"Ready Eagle go to red seven now."), share a target color ("Ready Tiger go to green nine now."/"Ready Eagle go to green six now/"), or differ in both color and number. The speaker of the target and distractor stream did not vary from trial to trial, and the two speakers were different genders. The fact that the speakers differed in gender meant differences in fundamental frequency could be used to help children select the appropriate stream, in addition to using the appropriate word (i.e., "tiger" rather than "eagle"). As many of the tasks included an aurally presented component, this provided an important aspect of interpreting performance.

Second, a nonverbal cognitive capacity measure, the Raven's Coloured Progressive Matrices (RCPM; Raven, 2000; Raven, Raven, \& Court, 1956), was included in the battery to measure general cognitive ability that is specifically non-linguistic. This 
assessment has norms for 5- to 11-year-old children and can be used by people who are mentally or physically impaired. It is relatively brief to administer, highly correlated with other intelligence measures for children (Martin \& Wiechers, 1954), and previously has been used in the assessment of children and adults with brain injury (Belanger $\&$ Vanderploeg, 2005; King, Hough, Walker, Rastatter, \& Holbert, 2006). Stimuli were presented using E-Prime. The completion of the RCPM was untimed for clinical interpretation; however, response times were recorded.

\section{Data analysis}

All data files were downloaded from a server and merged to facilitate batch data analysis. Participants were excluded if they had incomplete data (e.g., because of early termination of the study or failure to provide health history information). Of 74 participants tested (32 injured; 41 healthy), these criteria removed 13 (10 injured; 3 healthy) from the analysis. The injured participants considered for analysis are described in Table 1 below. In the planned analysis, a grand average performance was calculated and examined at a $\alpha=0.05$ level, two-tailed. This was done to determine that overall, group differences were present between the children with concussion and healthy children. Once this difference was determined to be significant, tasks individually were considered at $\alpha=0.05$, one-tailed, with recursive distribution of alpha, maintaining a study-wide $\alpha=0.05$ across multiple comparisons of the groups for each task. Only after an individual task met this standard, $\alpha=0.04$, were additional analyses of within-task variables considered. Nevertheless, the under-powered within-task comparisons are presented, despite being largely exploratory in nature. 
Table 1: Event characteristics of injured group

\begin{tabular}{llllll}
\hline Participant & $\begin{array}{l}\text { Days Post- } \\
\text { Injury }\end{array}$ & $\begin{array}{l}\text { Symptom } \\
\text { Score }\end{array}$ & $\begin{array}{l}\text { Part of } \\
\text { Head }\end{array}$ & LOC & Cause \\
\hline 1 & 18 & 5 & Left & 0 & Basketball \\
2 & 2 & 0 & Front & 0 & Hit in head by zipline \\
3 & 1 & 6 & Front-Left & 0 & Fall \\
4 & 18 & 1 & Front & 0 & Football \\
5 & 13 & 0 & Front & 0 & Running collision \\
6 & 13 & 0 & Back & 0 & Basketball \\
7 & 3 & 7 & Back & 0 & Football \\
8 & 20 & 24 & Front & + & Backflip into pool side \\
9 & 1 & 9 & Back-Left & 0 & Football \\
10 & 8 & 7 & Front & 0 & Swimming \\
11 & 19 & 17 & Top & 0 & Football \\
12 & 3 & 0 & Back & 0 & Fall \\
13 & 3 & 0 & None & 0 & Baseball \\
14 & 27 & 0 & Back & 0 & Soccer \\
15 & 9 & 11 & Front & 0 & Football \\
16 & 2 & 0 & Back & 0 & Hit head under sink \\
17 & 29 & 8 & Front & 0 & Jujitsu \\
18 & 9 & 20 & Neck & 0 & Hit in head \\
19 & 5 & 2 & Front & + & Running collision \\
20 & 11 & 8 & Front-Left & 0 & Fall in shower \\
21 & 3 & 19 & Right & + & Hit in head \\
22 & 21 & 36 & Front-Back & 0 & Basketball \\
\hline
\end{tabular}

Cause $=$ cause of injury, LOC $=$ loss of consciousness, Days post-injury $=$ number of days from reported injury to testing 


\section{Results}

\section{Group descriptions}

Groups were matched on age (injured: $M=8.94$ years, $S D=1.44$; healthy $M=$ 8.22 years, $S D=1.39 ; t(58)=1.924, p>0.05)$. The injured children tended to be slightly older, though this goes against any hypotheses about performance. Individuals with a recent injury reported significantly higher symptom scores (injured: $M=8.18, S D=9.62$; controls: $M=2.14, S D=5.12$; Levene's test for equality of variances: $p=0.004, t(28.58)$ $=2.71, p=0.01$, two-tailed). Among the injured participants, the mean number of days that a child was seen after injury was 10.82 days $(S D=8.73)$. Although initially planned because of the results of pilot testing, age-related group comparisons (comparing children under 7;11 compared to children over 8 years of age) presented here are purely exploratory in nature, as the final recruitment of young injured children did not provide sufficient power to examine this distinction meaningfully. A summary of performance differences between the injured and healthy groups is presented in Table 2 .

Table 2: Results summary

\begin{tabular}{llll}
\hline Task & Injured & Healthy & Effect size \\
\hline Category identification* & $73.5 \%(14.0 \%)$ & $80.1 \%(12.5 \%)$ & 0.50 \\
Phonological working memory* & $72.4 \%(15.4 \%)$ & $79.2 \%(10.4 \%)$ & 0.52 \\
Story recognition memory** & $48.8 \%(26.4 \%)$ & $63.9 \%(21.5 \%)$ & 0.63 \\
Sentence comprehension & $84.1 \%(21.5 \%)$ & $91.6 \%(15.2 \%)$ & - \\
Grammaticality judgment** & $75.7 \%(18.8 \%)$ & $86.3 \%(14.4 \%)$ & 0.63 \\
Rhyme identification & $57.6 \%(22.4 \%)$ & $60.7 \%(18.8 \%)$ & - \\
Auditory attention* & $53.8 \%(26.3 \%)$ & $65.7 \%(19.1 \%)$ & 0.52 \\
Non-verbal capacity* & $23.14(7.88)$ & $27.19(5.53)$ & 0.59 \\
\hline Performance accuracy results presented as mean(standard deviation). ${ }^{*} \mathrm{p}<0.05,{ }^{*} \mathrm{p}<$
\end{tabular}
0.01. The calculated effect size is Cohen's $d$. 


\section{Whole battery performance}

Across all tasks, children with a recent concussion injury $(M=66.3 \%$ accuracy, $S D=15.2 \%$ accuracy) performed more poorly than children with no history of concussion $(M=75.5 \%$ accuracy, $S D=10.8 \%$ accuracy; Levene's test for equality of variances: $p=0.03, t(33.49)=0.02$, two-tailed). This difference had a medium-large effect based on Cohen's $d$ of 0.70 . Response times in completing task trials correctly did not significantly differ for any task due to injury; although, across tasks, the time a given task took varied widely.

\section{Individual task performance}

\section{Category identification task.}

When asked to determine whether three visually presented items were members of a single category or not, significantly poorer performance was observed for injured participants than for healthy participants (injured: $M=73.5 \%, S D=14.0 \%$; healthy: $M=$ $80.1 \%, S D=12.50 \% ; t(57)=1.883, p=0.03$, one-tailed). This difference had a medium effect based on Cohen's $d$ of 0.50 . The average correct response time was 2.80 seconds $(S D=1.52$ seconds $)$. Injured participants $(M=2.66$ seconds, $S D=1.43$ seconds $)$ and healthy participants $(M=2.87$ seconds, $S D=1.56$ seconds $)$ performed similarly.

\section{Phonological working memory task.}

When asked to determine whether short streams of phonemes, those between three and six syllables long, were the same or different, injured participants performed significantly more poorly $(M=72.4 \%, S D=15.4 \%)$ when compared to healthy participants $(M=79.2 \%, S D=10.4 \%$; Levene's test for equality of variances: $p=0.05$, $t(32.63)=1.83, p=0.04$, one-tailed). This difference had a medium effect based on 
Cohen's $d$ of 0.52 . Participants also heard long streams of phonemes, between seven and eight syllables long, though group differences with these more challenging stimuli were not significant (injured: $M=62.5 \%, S D=16.4 \%$; healthy: $M=66.6 \%, S D=14.7 \%$; $t(57)=0.98, p>0.3)$

The average correct response time was 6.30 seconds for short streams $(S D=1.70$ seconds) and 4.39 seconds ( $S D=2.31$ seconds) for long streams. It is possible that the greater variability in response time for longer items reflected a somewhat bimodal trend, wherein some children with concussion were guessing while others were able to complete the task similarly to healthy children. Across groups, participants performed similarly in both the short (injured: $M=6.32$ seconds, $S D=2.33$ seconds; healthy: $M=6.29$ seconds, $S D=1.23$ seconds) and long (injured: $M=4.62$ seconds, $S D=3.50$ seconds; healthy: $M$ $=4.26$ seconds, $S D=1.22$ seconds) conditions.

\section{Story recognition memory task.}

Participants were asked first to listen to a brief story in which a target word was identified for each sentence (e.g. "I felt something lick my nose. Remember nose."). Then they were presented with two images, one representing the target word and another representing a plausible foil (e.g., a nose and an eye), and asked to recognize which of the two images had been the target. There was a significant difference in accuracy between the groups, with injured participants $(M=48.8 \%, S D=26.4 \%)$ performing significantly more poorly than healthy participants $(M=63.9 \%, S D=21.5 \% ; t(57)=2.399, p=0.01$, one-tailed). This difference had a medium effect based on Cohen's $d$ of 0.63 . The average correct response time was 2.58 seconds $(\mathrm{SD}=0.96$ seconds). Injured participants $(M=$ 
2.51 seconds, $S D=1.05$ seconds $)$ and healthy participants $(M=2.62$ seconds, $S D=0.92$ seconds) performed similarly.

As items were presented in a consistent order, an item analysis was done to explore the task for effects of memory, such as primacy and recency, as well as to understand whether items more integral to the story plot or those with more plausible foils were associated with different rates of accuracy across groups (see Figure 2). Group differences per item were significant only for items $7\left(\chi^{2}=5.083, p=0.024\right.$, two-tailed, $d f=1), 8\left(\chi^{2}=5.497, p=0.019\right.$, two-tailed, $\left.d f=1\right)$, and $10\left(\chi^{2}=3.920, p=0.048\right.$, twotailed, $d f=1)$. They were not significant for items $1-6,9$, or 11 . Performance on the first two items was poor for all children (17\% and $27 \%$ across groups, respectively), suggesting they may not yet have grasped the task. As significant group differences tended to be later in the task, this may suggest that children with concussion experienced a more rapid fatigue, resulting in more difficulty as the task continued.

\section{Sentence comprehension task.}

Participants were asked to determine which of three visually presented scenes best corresponded to a sentence that was spoken and presented on the screen. Groups approached significance to the extent that they differed with respect to accuracy (injured: $M=84.1 \%, S D=21.5 \%$; healthy: $M=91.6 \%, S D=15.2 \% ; t(57)=1.57, p=0.06$, onetailed). This difference had a low-medium effect based on Cohen's $d$ of 0.40 . The average correct response time was 9.21 seconds $(S D=3.94$ seconds $)$. Injured participants $(M=9.22$ seconds, $S D=3.63$ seconds $)$ and healthy participants $(M=9.20$ seconds, $S D=$ 4.10 seconds) performed similarly. 
Figure 2: Story recognition memory item analysis

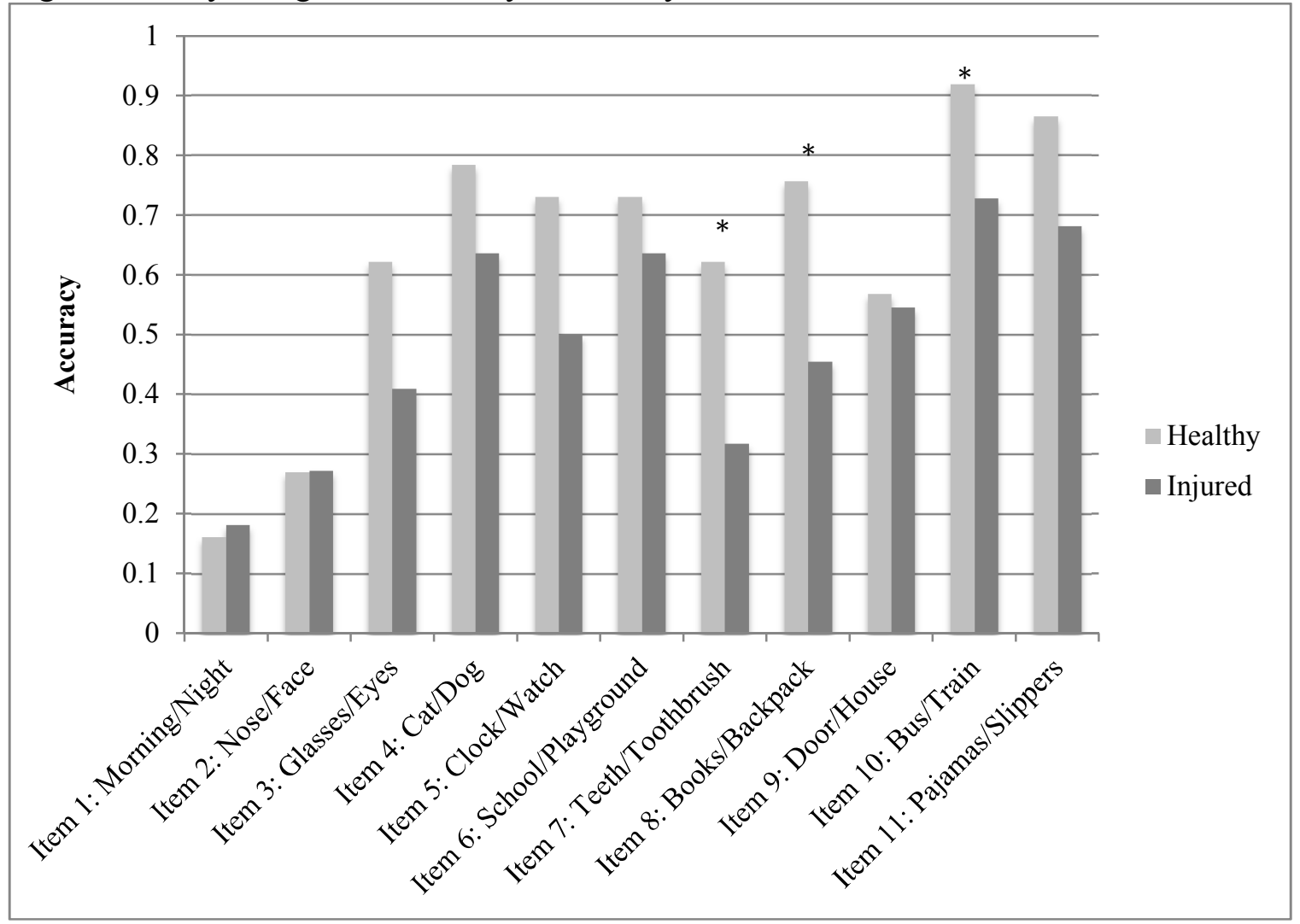

Note: Items are presented in the order they occurred both in the story and in the recognition task. The item number is followed by the target word, then the foil, despite the position of the target and the foil being randomized in their presentation.

\section{Grammaticality judgment task.}

When asked to determine whether a spoken sentence was grammatically correct, injured participants performed significantly more poorly $(M=75.7 \%, S D=18.8 \%)$ compared to their healthy peers $(M=86.3 \%, S D=14.4 \%$; Levene's test for equality of variance: $p=0.03, t(35.40)=2.29, p=0.01$, one-tailed). This difference had a medium effect based on Cohen's $d$ of 0.63 . The average correct response time was 4.24 seconds ( $S D=2.56$ seconds). Injured participants $(M=4.41$ seconds, $S D=3.55$ seconds $)$ and healthy participants ( $M=4.16$ seconds, $S D=1.85$ seconds) performed similarly, except that injured participants' response times were more variable. 
Participants listened to sentences that could be grammatically correct or incorrect in one of four distinct ways: use of double auxiliaries, verb agreement, tag question pronoun and noun agreement, or tag question auxiliary agreement. As performance on the judgment task as a whole was significantly different between groups, these grammatical error types were explored individually for their contribution to the main effect. The difference between performance by injured and healthy participants appeared to be driven by differing performance in double auxiliaries (injured: $M=76.8 \%, S D=23.4 \%$; healthy: $M=91.5 \%, S D=13.5 \%$, Levene's test of equality of variances, $p=0.02$, $t(29.29)=2.70, p<0.01$, one-tailed), verb agreement (injured: $M=81.8 \%, S D=18.7 \%$; healthy: $M=90.8 \%, S D=16.0 \%, t(58)=1.97, p=0.027$, one-tailed), and tag auxiliaries (injured: $M=67.7 \%, S D=18.5 \%$; healthy: $M=78.4 \%, S D=19.5 \% ; t(58)=2.08, p=$ 0.02 , one-tailed). Differences in tag pronouns were not significant (injured: $M=76.4 \%$, $S D=20.8 \%$; healthy: $M=84.5 \%, S D=20.7 \% ; t(58)=1.46, p>0.1)$.

\section{Rhyme identification task.}

Participants were asked to consider a set of three visually presented items (e.g., an image of a bee, a knee, and a horse), identify which two represented words that rhymed ("bee" and "knee") and then select the image that did not represent a rhyming word (e.g., an image of a horse). Groups did not differ with respect to accuracy (injured: $M=57.6 \%$, $S D=22.4 \%$; healthy: $M=60.7 \%, S D=18.8 \% ; t(56)=0.58, p=0.57)$. This difference had a very small effect based on Cohen's $d$ of 0.15 . The average correct response time was 5.54 seconds ( $S D=2.02$ seconds). Injured participants $(M=5.60$ seconds, $S D=2.14$ seconds) and healthy participants ( $M=5.51$ seconds, $S D=1.96$ seconds $)$ performed 
similarly. Performance in general was quite poor, suggesting this may have been a very difficult task for all children in the experimental age range.

\section{Auditory attention task.}

When asked to follow one of two spoken instructions presented simultaneously to select one of four possible target locations, injured participants performed more poorly than healthy participants (injured: $M=53.8 \%, S D=26.3 \%$; healthy: $M=65.7 \%, S D=$ 19.1\%; Levene's test for equality of variances: $p=0.007, t(34.0)=1.86, p=0.04$, onetailed). This difference had a medium effect based on Cohen's $d$ of 0.52 . Among the auditory attention trials, contrasting instructions could share a target number ("Ready Tiger go to blue seven now."/"Ready Eagle go to red seven now."), share a target color ("Ready Tiger go to green nine now."/"Ready Eagle go to green six now/"), or differ in both color and number. Across groups, trials sharing neither a color nor number were associated with the highest accuracy (63.6\%), while those sharing a color but not a number were associated with the lowest accuracy (57.1\%). Injured participants performed significantly more poorly than healthy controls when the target number was the same as the foil (injured: $M=52.8 \%, S D=27.3 \%$; healthy: $M=66.1 \%, S D=23.9 \%, t(58)=$ 1.97, $p=0.03$, one-tailed) and when the target color was the same as the foil (injured: $M$ $=48.9 \%, S D=29.6 \%$; healthy: $M=61.8 \%, S D=26.0 \%$; $t(58)=1.77, p=0.04$, onetailed). Trials sharing neither the number nor color did not differ between groups (injured: $M=56.8 \%, S D=27.7 \%$; healthy: $M=67.6 \%, S D=19.7 \%$; Levene's test for equality of variances: $p=0.001, t(33.4)=1.60, p=0.06$, one-tailed). Thus, while the injured children did worse overall, it is unclear that there is a meaningful interaction effect between trial type and injury. The average correct response time was 5.33 seconds 
$(S D=1.96$ seconds). Although injured participants took slightly more time $(M=5.73$ seconds, $S D=2.76$ seconds $)$ than healthy participants $(M=5.10$ seconds, $S D=1.29$ seconds), this difference was not significant.

\section{Raven's Coloured Progressive Matrices.}

Average performance on the Raven's Coloured Progressive Matrices (RCPM) across groups was $25.68(S D=6.74)$, between the $50^{\text {th }}$ and $75^{\text {th }}$ percentile based on the average age of the individuals tested. Injured participants demonstrated significantly poorer performance $\left(M=23.14, S D=7.88\right.$, between $25^{\text {th }}$ and $50^{\text {th }}$ percentile $)$ compared to healthy participants $\left(M=27.19, S D=5.53,75^{\text {th }}\right.$ percentile; Levene's test for equality of variances $p=0.032, t(33.43)=2.121, p=0.02$, one-tailed). This difference had a medium effect based on Cohen's $d$ of 0.59 . The average correct response time was 7.37 seconds $(S D=4.77$ seconds $)$. Injured participants $(M=7.48$ seconds, $S D=5.55$ seconds $)$ and healthy participants ( $M=7.32$ seconds, $S D=4.33$ seconds $)$ performed similarly.

\section{Predicting injury based on performance}

Performance across verbal tasks was highly correlated, which was anticipated considering the interconnected nature of linguistic skills. Despite this finding, exploration of the data suggests outliers did not drive these correlations where significant (see Figure 3). To address this limitation and reduce the overall number of variables considered for predictive modeling, performance on verbal tasks showing significant group differences (category identification, phonological working memory, story recognition memory, grammaticality judgment, and auditory attention) were entered into a factor analysis of primary components along with self-reported symptom score to perform data reduction. Correlations among variables are reported in Table 3 and demonstrate moderate 
Figure 3: Correlation scatterplot matrix for selected tasks across groups

\begin{tabular}{|c|c|c|c|c|c|c|}
\hline 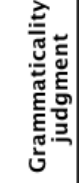 & & 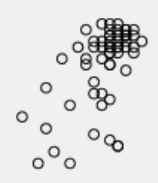 & 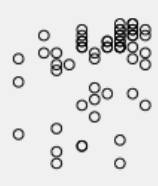 & 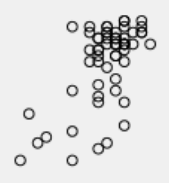 & 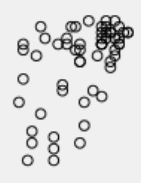 & 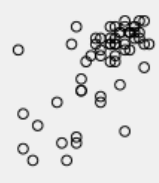 \\
\hline 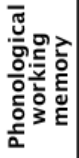 & 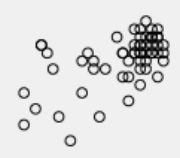 & & 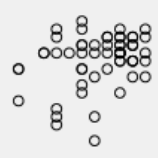 & 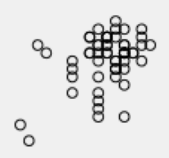 & 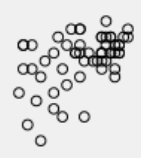 & 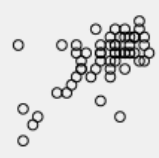 \\
\hline 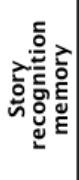 & 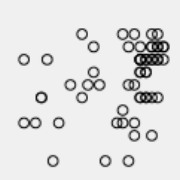 & 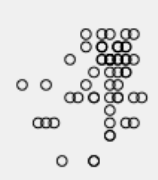 & & 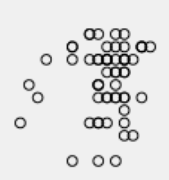 & 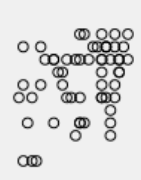 & 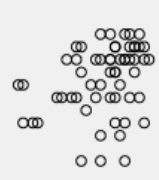 \\
\hline 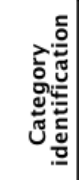 & 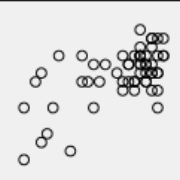 & 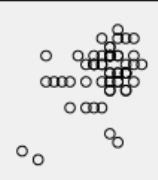 & 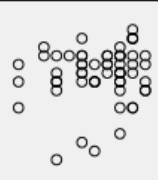 & & 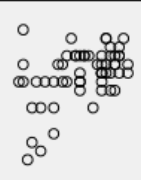 & 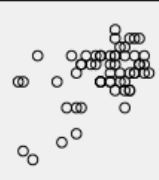 \\
\hline 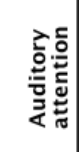 & 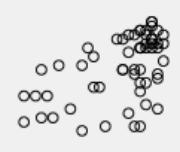 & 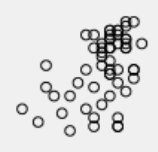 & 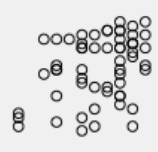 & 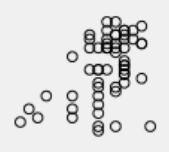 & & 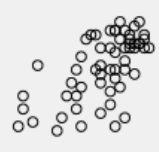 \\
\hline$\widetilde{\simeq}$ & 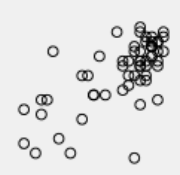 & 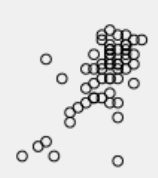 & 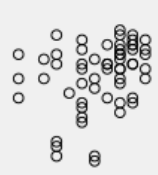 & 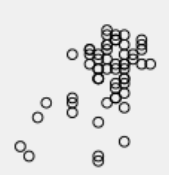 & 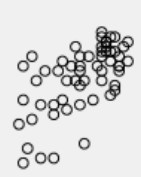 & \\
\hline & $\underset{\text { judgment }}{\text { Grammaticality }}$ & $\begin{array}{l}\text { Phonological } \\
\text { working } \\
\text { memory }\end{array}$ & $\begin{array}{c}\text { Story } \\
\text { recognition } \\
\text { memory }\end{array}$ & $\begin{array}{c}\text { Category } \\
\text { identification }\end{array}$ & $\begin{array}{l}\text { Auditory } \\
\text { attention }\end{array}$ & PCM \\
\hline
\end{tabular}

Table 3: Pearson correlation matrix

\begin{tabular}{lccccccc}
\hline & Symptom Score & Gram & Phon & RCPM Story & Cat & Auditory Attn \\
\hline Symptom score & - & .027 & -.009 & .007 & -.055 & -.047 & -.230 \\
Gramm & .027 & - & $.565^{* *} .675^{* *} .352^{* *} .615^{* *}$ & $.525^{* *}$ \\
Phon & -.009 & $.565^{* *}$ & - & $.626^{* *}$ & $.306^{*}$ & $.420^{* *}$ & $.470^{* *}$ \\
RCPM & .007 & $.675^{* *}$ & $.626^{* *}$ & - & $.314^{*}$ & $.492^{* *}$ & $.623^{* *}$ \\
Story & -.055 & $.352^{* *}$ & $.306^{*}$ & $.314^{*}$ & - & .130 & $.366^{* *}$ \\
Cat & -.047 & $.615^{* *}$ & $.420^{* *} .492^{* *}$ & .130 & - & $.461^{* *}$ \\
Auditory Attn & -.230 & $.525^{* *}$ & $.470^{* *} .623^{* *} .366^{* *} .461^{* *}$ & - \\
\hline
\end{tabular}

Gram $=$ grammaticality judgment task, Phon $=$ phonological working memory task, Story $=$ story recognition memory task, $\mathrm{Cat}=$ category identification task; $* *=$ correlation is significant at the 0.01 level (two-tailed), $*=$ correlation is significant at the 0.05 level (two-tailed) 
correlations consistent with retaining all previously selected variables. Additional calculations revealed that sampling adequacy and sphericity assumptions of the factor analysis were met (Kaiser-Meyer-Olkin measure of sampling adequacy $=0.807$; Bartlett's test of sphericity approximate $\chi^{2}=138.37, p<0.001, d f=21$ ). Eigenvalues are illustrated in Figure 4. Eigenvalues greater than 1 were extracted, resulting in two components. Component 1 had a high positive correlation with all verbal tasks except Figure 4: Factor analysis eigenvalues

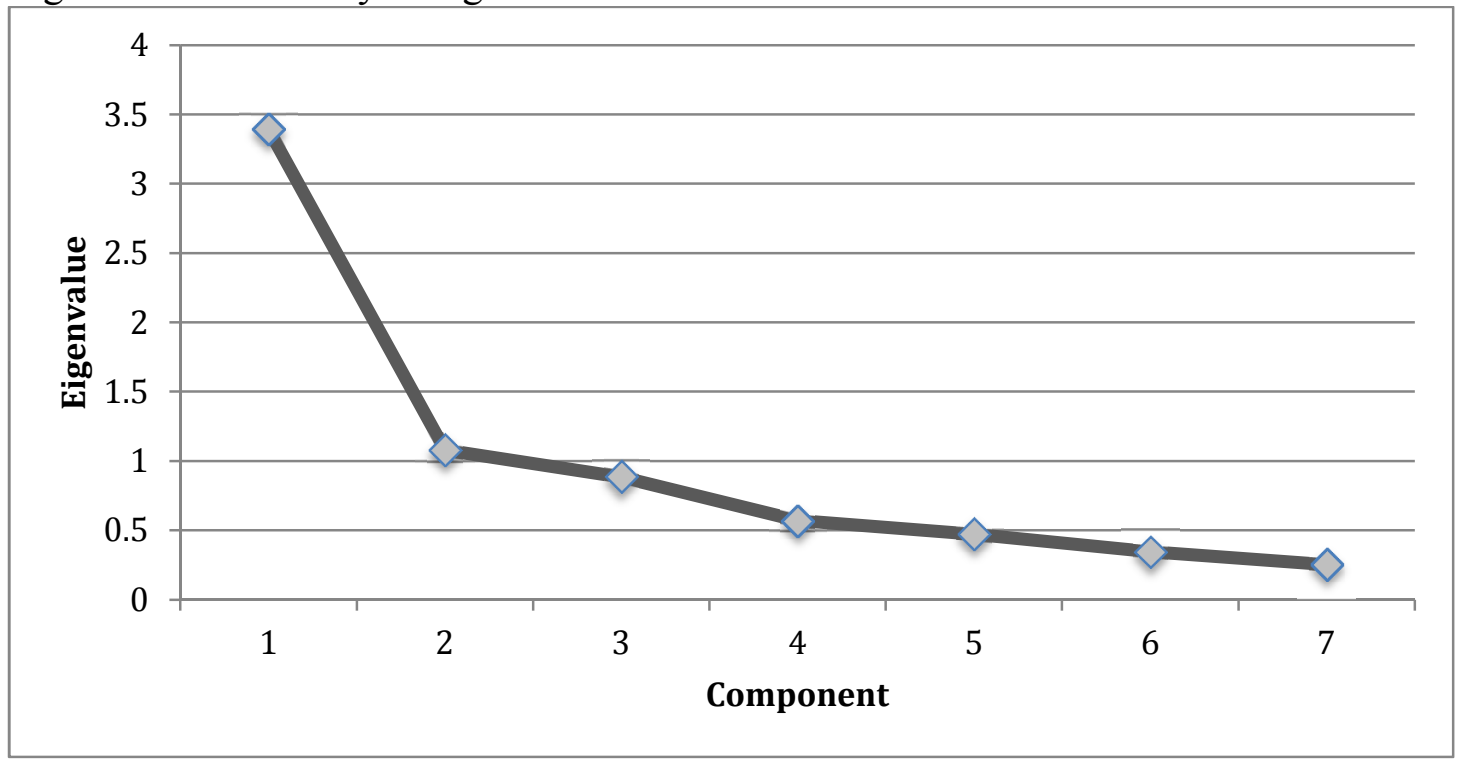

story recognition memory. Component 2 had a high positive correlation with selfreported symptom score (see Table 4). This suggests that the verbal and cognitive tasks, though considered theoretically different, to some degree were all capturing the same underlying skill. This is consistent with the high correlations observed among tasks.

Recognizing the limitations in interpreting factor analysis given the relatively modest sample size (MacCallum, Widaman, Zhang, \& Hong, 1999; Mundfrom, Shaw, \& $\mathrm{Ke}, 2005)$ and informed by findings from the factor analysis suggesting that these tasks captured a single central capacity, a second analysis was conducted in which verbal tasks 
producing significant group differences were averaged to generate a verbal performance quotient.

Table 4: Component matrix

\begin{tabular}{lcc}
\hline & Component \\
\cline { 2 - 3 } & 1 & 2 \\
\hline Raven's Coloured Progressive Matrices & .854 & .111 \\
Grammaticality judgment & .846 & .178 \\
Auditory Attention & .779 & -.289 \\
Phonological working memory & .767 & .104 \\
Category identification & .707 & .098 \\
Story recognition memory & .496 & -.171 \\
Symptom score & -.089 & .950
\end{tabular}

In order to examine the value of considering the average verbal task performance over and above the value of the symptom score alone when controlling for age, a binary logistic regression was conducted in which these variables were added in a stepwise fashion. A test of the symptom score alone when controlling for age produced a significant model $\left(\chi^{2}=11.18, p<0.001, d f=3\right)$. Nagelkerke's $R^{2}$ of 0.233 indicates a modest relationship between prediction and grouping. Prediction success overall was $75 \%$, suggesting that the level of self-reported symptoms was a decent, but not perfect, predictor of diagnosis. Troublingly, although this statistic represented $92.1 \%$ accuracy in healthy participants, it correctly predicted only $45.5 \%$ of participants with mTBI, which provided strong evidence to suggest that diagnosis of concussion was based on factors beyond self-reported symptoms. When verbal quotient was added to the model, the improvement was considerable $\left(\chi^{2}=25.72, p=0.004, d f=2\right.$; Nagelkerke's $R^{2}$ of 0.477$)$. Prediction success increased overall to $81.7 \%$, crucially improving to $68.2 \%$ for participants with a recent injury ( $89.5 \%$ for healthy participants). Verbal quotient was a significant predictor of injury status after controlling for age and symptom score (Wald $=$ 
$8.433, \mathrm{p}=0.004)$, underscoring the added value of novel verbal assessments. These findings were further affirmed by a conceptually similar set of analyses using a discriminant analysis with leave-one-out cross-validation. The inclusion of the verbal quotient improved classification performance from $70.0 \%$ to $80.0 \%$.

\section{Effort measurements}

Self-reported effort scores differed only on the category membership and phonological working memory tasks. In both tasks, participants with a recent concussion reported significantly greater effort. In identifying whether three images belonged to the same semantic category, participants with a recent concussion reported an average effort of $2.63(S D=1.30)$, while healthy participants reported an average effort of $1.68(S D=$ $0.82, t(43)=2.66, p=0.01)$. Phonological working memory was considerably more difficult for participants with a recent injury, who rated it at 4.38 on average $(S D=0.74)$, than for healthy participants, who rated it at $2.62(S D=1.28 ; t(43)=3.73, p=0.001)$. 


\section{Discussion}

The purpose of this study was to inform the creation of a screening tool for individuals with concussion based on developing language skills. One rationale for the current study was to be able to examine relative areas of strength and weakness in language skills following concussion in order to best serve this population's needs in a variety of communication contexts. Here, we observed deficits that affected children with concussion at the lexical, sentence, and domain general levels of performance. Children with concussion performed significantly more poorly when rapidly: 1) determining whether three images belonged to the same category; 2) determining whether two wordlength syllable strings spoken by two different speakers were the same or different; 3 ) recognizing targets spoken in a brief story; 4) determining whether a spoken sentence was grammatically correct; 5) following a single speaker's directions when two speakers presented directions simultaneously; and 6) examining visually presented patterns to determine the appropriate tile to complete the pattern. Each of these differences was of a moderate effect size. Children with concussion were not different from their peers of the same age in global sentence comprehension (determining which of three similar images an aurally and visually presented sentence best matched), nor were they different from their peers in rhyme identification (identifying the odd item out of a set of three items, two of which rhymed). However, the general pattern observed from these data was that children with a recent concussion were impaired in many different areas of language, suggesting that the effects of injury extend across a wide range of skills. Clear evidence of differentially affected language skills, some more robust and some more vulnerable to injury, was not observed based on the results of this study. 


\section{Evidence for lexical-level deficits}

Considering first the implications of these findings at the single word, or lexical, level of language, the present study contributes to the understanding and interpretation of the previous finding that children with brain injuries have demonstrated impaired category fluency in production tasks (Ewing-Cobbs et al., 1987) and difficulties with accessing and utilizing phonological representations of words, as previously demonstrated in a reading paradigm (Barnes et al., 1999). Our findings lend support to an account that lexical-level effects are largely due to difficulties accessing information. Although impaired ability to name items within a category has been reported previously, our findings suggest that even following a very mild injury, children may have difficulty and require more effort simply identifying whether a category is being represented, suggesting a slightly different point of disruption in the semantic system. The contrast between the observed differences in naming and the null finding in rhyming may lend support to the interpretation that deficits in generating and producing names of visually presented objects are due to a breakdown at the level of semantic, rather than stored phonological, representation.

Both the phonological working memory task and rhyme identification task utilized phonological representations, through auditory analysis and phonological input and through stored phonological information about known words, respectively. Children with a recent concussion performed more poorly on the phonological working memory task and found it significantly more effortful than their uninjured peers. However, they did not perform more poorly than their healthy peers on the rhyme identification task. This pattern suggests that although children may be accessing known phonological word 
forms, as seen in Barnes et al. (1999), they have difficulty at the level of interpreting input from the speech stream sound by sound. This interpretation is further supported by evidence from the auditory attention task, in which children with concussion performed more poorly across the board.

\section{Evidence for other linguistic deficits}

Prior work in this population consistently has shown that children with a history of brain injury produce language more poorly than children with no history of injury. This may include using fewer essential story components (e.g., setting, action), fewer pieces of essential information (Biddle et al., 1996; Chapman et al., 1992; Ewing-Cobbs et al., 1998), and fewer transitions (e.g., first, then, next, later) when recounting events or telling stories. Injured children also use a greater proportion of ambiguous referents (e.g., saying, "then they went to the party" without previously identifying who "they" are). However, how to best characterize these production deficits is unclear. It is possible that these observations are simply the result of underlying lexical problems, but it is also possible that they reflect deficits over and above what would purely be expected from deficits at the word level, suggesting specific impacts to syntax in a receptive task. In the present study, children with concussion had increased difficulty identifying when syntactic violations of agreement took place compared to healthy children. Specifically, children with a recent concussion demonstrated more difficulty identifying when an error involved double auxiliaries (“Are Amanda and Tom are going to the store?"), verb agreement ("Peter and Sarah is ready to paint."), and tag question auxiliary agreement (“John is very tall, doesn't he?"). This finding suggests that the children are having problems beyond simply the effects of deficits in lexical processing. It is possible that 
the injured children simply were not able to sufficiently attend to the auditory stream to note these errors or that syntactic errors that do not block comprehension of the sentence's meaning are overlooked by children with concussion, but it also is possible that poorer performance on this grammaticality judgment task directly reflects a true underlying syntactic deficit, which is also contributing to the pattern of production difficulties reported in the existing literature.

Prior research also has noted decreased passage comprehension, specifically linked to word identification and processing (Barnes et al., 1999; Biddle et al., 1996). Here we observed that, although comprehension of simple sentences was not significantly different between children with concussion and healthy children, children with concussion demonstrated difficulty utilizing information in situations that taxed their working memory, as seen in the story recognition memory task. The absence of an observed difference on the sentence comprehension task may have been the result of a considerable ceiling effect, which was observed in both groups, raising a question as to whether sentence comprehension difficulties would be observable in stimuli of greater length and complexity. Interestingly, although differences in performance on the RCPM were noted, difficulties in visual processing did not appear to hinder performance by concussed children in examining and comparing the minimally different visual scenes associated with the sentence comprehension task. In story recognition, the task was fairly simplified with the hope of minimizing the memory load; however, children with a recent injury still performed below chance. Although it is possible that children with concussion struggled with this task because it required memory of specific details from the story, it also may be that the children with injury were not able to take advantage of 
the narrative components to improve recognition and recall of the story because of deficits in language comprehension.

The theory that difficulties on this task were the result of deficits in memory of specific details may be supported by observations from the item analysis. On the majority of items, group differences trended toward children with concussion performing more poorly; however, the differences only were significant for three items: 7 (teeth/toothbrush), 8 (books/backpack), and 10 (bus/train). For items 7 and 8 , children may have had difficulty due to the fact that the foil was implied in the sentence from the story, even though the foil was not the stated target word. In item 7, the sentence is "I brushed my teeth. Remember 'teeth." Here, the word toothbrush never appears, but the sentence does elicit the implied use of a toothbrush through a bridging inference to the necessary instrument for brushing one's teeth. As such, one's mental representation of the event probably included the "toothbrush," even though the word itself was never stated in the story. Similarly, though distinct, in item 8, the sentence is "I grabbed my books. Remember 'books." Here, too, the foil word is implied functionally. However, a backpack is a frequently used container in that context, rather than a necessary instrument. For children who themselves use backpacks to carry their books, this relationship may result in the mental representation of the event including the backpack. If the children with concussion only remembered the gist of the story and not the specific target words, these foils would be very challenging because they are both true of the event representations, despite only the target being present in the spoken text. In contrast, the target and foil pair in item 10, bus versus train, involves two plausible but different words within the same category (two modes of transportation). Either a bus or a train was 
possible given the story, but the use of the word bus does not bring to mind something about a train having been part of the story. The fact that both types of errors occurred suggests that the problem in this task is not simply that the children had difficulty distinguishing their representation of the event from the actual words produced. In each of these cases, errors suggest difficulties recognizing specific details from the story, and a reliance on the overall substance of what was remembered.

\section{Evidence for broader cognitive deficits}

Across tasks, performance by the injured group not only provides notable evidence for deficits in accessing the semantic information for words and explicitly utilizing knowledge of syntax, but also suggests deficits in broader cognitive skills. Prior research has highlighted the role of domain general deficits in working memory, executive function, or core cognitive capacity in children with a history of brain injury (Borgaro et al., 2003; Ewing-Cobbs et al., 1998). However, relatively little has been done to examine these dimensions in concussed children. Here, we observed that children with concussion performed the RCPM more poorly than age-matched children with no concussion history, suggesting deficits in visuo-spatial processing and problem-solving. This underlying deficit in problem solving may have pervaded many of the otherwise linguistic tasks. For all tasks, responses were selected from a closed set rather than generated. If the child had proficient problem-solving skills, one would imagine that the child could employ those skills (e.g., process of elimination) to reduce the set of possible responses further and improve chances of an accurate response. However, if a child had deficits in problem solving, then utilizing this information in rapidly responding to questions could be more difficult. Thus, if the child with a concussion could not respond 
correctly based on the prompt and their knowledge or language access itself, they would likely be further hindered even when, essentially, "guessing" because other strategies also were not being employed. This potential interpretation of performance gains some support from the observation that the RCPM performance significantly correlated with performance in all verbal tasks, with all but one exceeding a $p=0.01$ level, two-tailed.

The auditory attention task also correlated highly with all tasks exceeding a $p=$ 0.01 level, two-tailed, suggesting selectively attending to and parsing information also may be affected in children with concussion. It is unclear from these findings whether the central deficit in this domain is because of difficulties separating the two streams of spoken information from one another or because of difficulties attending to one stream in particular. Previous studies have emphasized the potential role of deficits in processing fundamental frequency, important to listening in noise, in children with concussion (N. Kraus et al., 2017; N. Kraus et al., 2016). Viewed through this lens, it would suggest that performance in the present auditory attention task might have been hindered considerably by difficulties distinguishing the two voices since pitch often is an important cue used in stream segregation. Beyond this, there is additional evidence that may support the interpretation that selective attention was the core deficit impacting performance. In the story memory task, selective attention also could explain the difficulty children with concussion appeared to demonstrate when asked to recognize details from the story beyond simply understanding the language being used or understanding the overall story content. This central deficit also could explain difficulties in the grammaticality judgment task, in which the child may have insufficiently filtered the content of the sentence to effectively monitor for the error. Prior research has identified deficits in auditory 
attention (Bernstein, 2002; Blanchet et al., 2009) in young adults with mTBI. Similarly, a deficit in visual selective attention has been proposed by some authors as another characteristic of the concussion profile (Howell, Osternig, Van Donkelaar, Mayr, \& Chou, 2013; Moore et al., 2016). Despite frequent null behavioral differences (Baillargeon, Lassonde, Leclerc, \& Ellemberg, 2012; Mayer et al., 2012; Stablum, Mogentale, \& Umiltà, 1996), it seems highly likely that underlying processes both for auditory and for visual selective attention are more effortful even when performance differences between healthy and concussed children are not significant (Rogers, Fox, \& Donnelly, 2015). 


\section{Conclusion \& Future Directions}

While some may argue that language findings are wholly secondary or, at least, largely irrelevant in comparison to general cognitive impairment, examining performance in different dimensions of language results in fundamentally different implications than cognitive dimensions alone. Here, children showed deficits in the performance of a wide array of linguistic tasks. These results lend strong support to the growing evidence that children recovering from a recent concussion would benefit from speech-language evaluation that captures a richer and more detailed profile of communicative functioning than neuropsychological evaluation. Although, or perhaps, because areas of relative strength and weakness in language skills following concussion were difficult to parse in this study due to highly correlated performances, a speech-language evaluation would inform immediately beneficial, if potentially short-term, academic accommodations. Concerns about re-entering the rigors of academic participation are particularly relevant considering that cutting-edge research has led diverse clinicians working in concussion management to question the long-standing wisdom of recommending a sustained period of so-called "cognitive rest," or limited participation in perceived intellectual, in contrast with physical, activities. These intellectual activities include academic participation, but also include activities such as communicating with peers or watching television (Halstead, Brown, \& McAvoy, 2017). Thus, as children are returning to and participating in educational activities, identifying the tasks that are most difficult would allow for them to receive the most appropriate accommodations and support. Moreover, the process of seeking evaluation from a speech-language pathologist also may assist in establishing a structure in place in the classroom to monitor and address linguistic deficits that may 
present themselves over time as mild deficits in language are met with increasing academic demands.

Somewhat unique to this project was the approach from a developmental language perspective (i.e., asking, "what may be difficult for a child in this age range?") rather than the more common clinical injury and rehabilitation perspective (i.e., "what of the things that are difficult for more severely brain injured children would still be difficult even if a child had the most mild form of injury?"). This led to examining a different set of skills from the onset. Tasks were selected to capture emerging or developing language skills. Perhaps as a result, the present research elucidated a number of previously unreported skills that are more challenging for children with concussion than their similarly aged peers with no history of head injury. These newly identified deficient skills complement and inform what is currently known about language and cognitive-linguistic performance in concussed children. Based on these findings, one may recommend that, within the recovery period following concussion, specific care be given to limiting auditory memory load. This could be accomplished by presenting information in multiple modalities (e.g., age-appropriate visual reinforcements for spoken instructions), providing quiet listening environments and minimizing auditory distractions, particularly when verbally providing new information (Blanchet et al., 2009), limiting verbal instructions to simple one- or two-step commands in the absence of multimodal supports, and assisting the child in rehearsal and self-management techniques (e.g., having the child check understanding by repeating instructions back to the speaker). Likewise, children recovering from concussion may benefit from additional support when completing classroom activities, particularly writing and interpretation of others' work, when 
difficulties in semantic access may be present due to the injury. Support for this skill may include things like word banks or written prompts; however, where possible, it may be advisable simply to delay complex linguistic assessments, such as major written assignments, until the child has demonstrably recovered.

Linguistic and cognitive-linguistic measures of considerable difficulty produce observable differences in pediatric patients with concussion. These methods provide one way of supplementing a subjective symptom reporting-based approach to managing concussion, which recently has been criticized for susceptibility to exaggerated reporting, particularly in children (Schechter, Araujo, \& Dodd, 2015). Presently, based on these findings, tools for screening children with concussion based on linguistic skills are in development at the University of Maryland. Future directions for this research will include additional testing of tasks administered through a tablet interface designed to emulate a child's game. It is our hope that this will further inform the development of tools to assist children with concussion in receiving the support they need academically while they recover from injury. 


\section{Appendix A: Sample Experimental Stimuli}

\section{Rhyme identification task}

Participants viewed 3 images and were asked to select the one that represented a word that did not rhyme with one of the other two. In the example below, "bee" and "knee" rhyme, while "horse" does not. Therefore, the correct response was to select the horse.
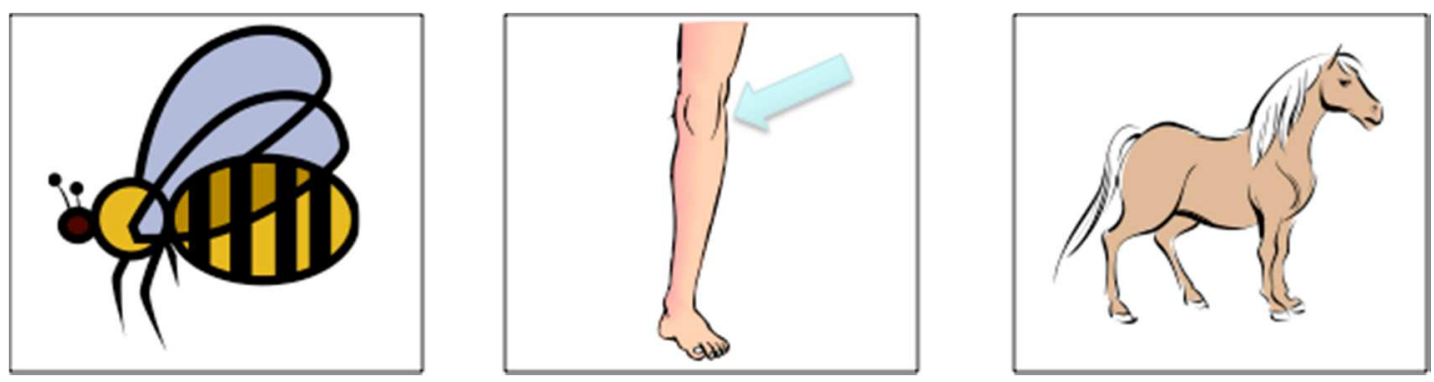

\section{Onset identification task}

Participants viewed 3 images and were asked to select the one that represented a word that did not share the same onset with one of the other two. In the example below, "game" and "girl" share the first sound/g/, while "house" does not. Therefore, the correct response was to select the house.
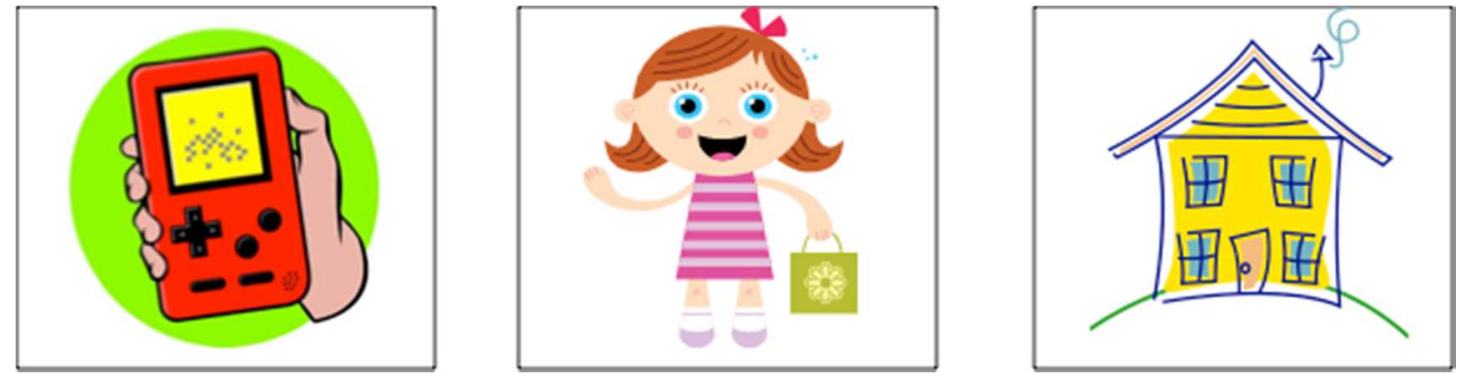


\section{Category identification task}

Participants viewed 3 images and were asked to examine each one and determine whether together the three were members of a supraordinate category or not. Participants also saw a smiling face and a frowning face on screen and were instructed to select the smiling face if the three images belonged to the same category and to select the frowning face if not. In the example below, an apple, a banana, and grapes are all fruits. Therefore, the correct response was to select the smiley face because all three belonged to a single category.

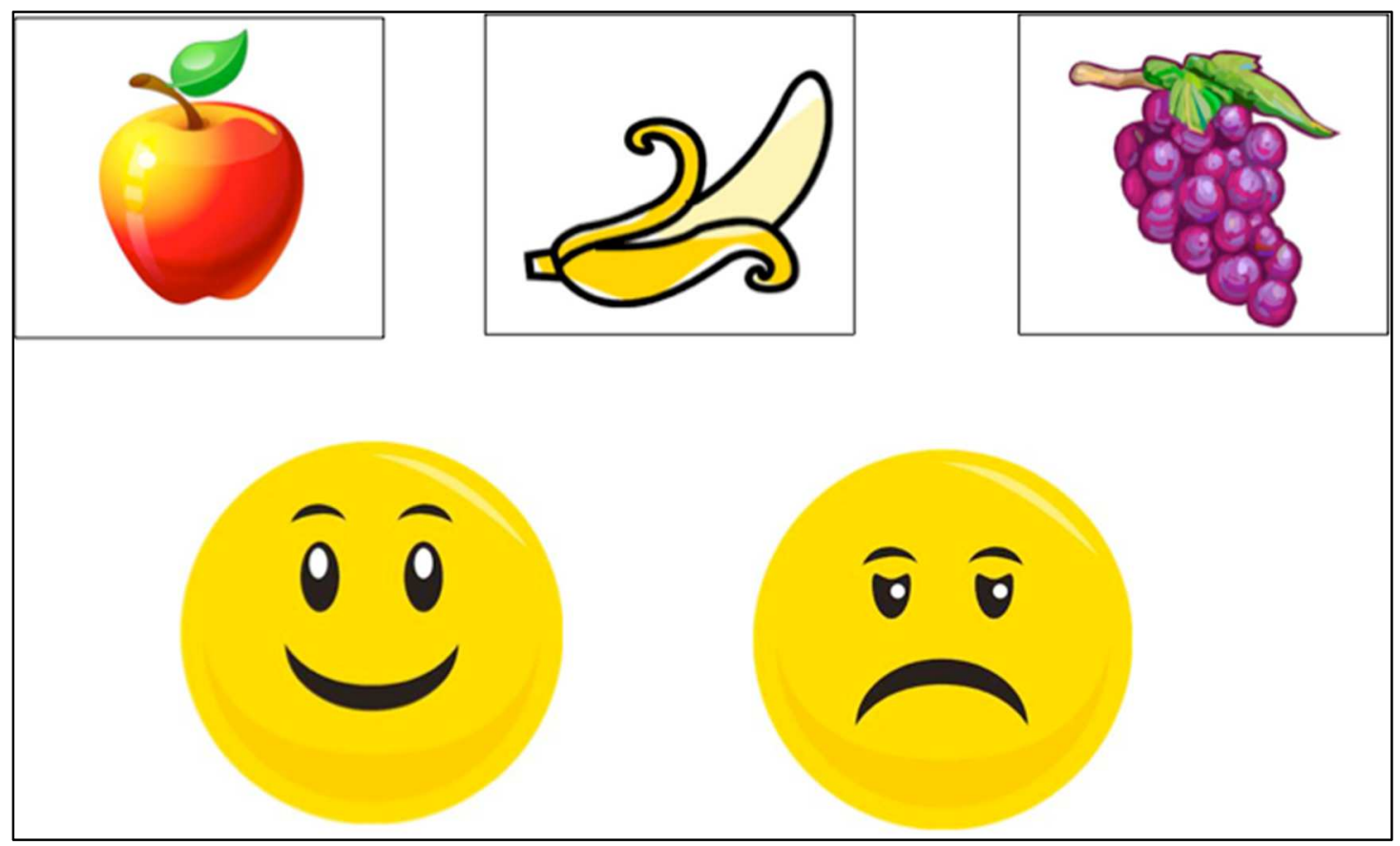




\section{Sentence comprehension task}

Participants viewed 3 images and were asked to select the one that best represented the meaning described in a sentence presented both on screen and read aloud. In the example below, the sentence "The girl is jumping over the cat under the bridge" was read aloud as it appeared on screen. The images consist of, from left to right, a girl jumping over a cat under a bridge, a girl jumping over a cat over a bridge, and a girl jumping over a cat on a bridge. Therefore, the correct response was to select the first image, as this best reflected the meaning of the sentence.

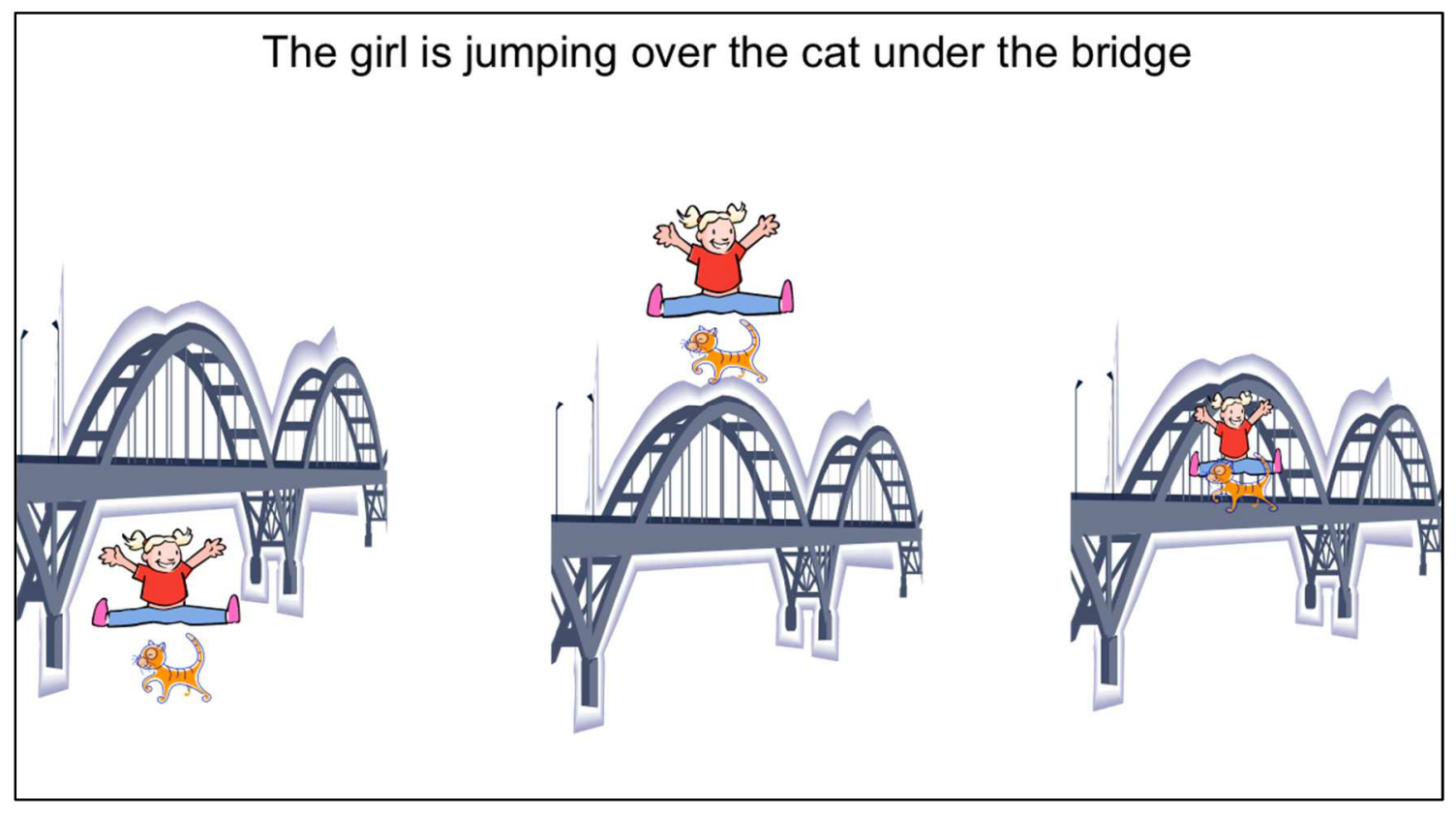




\section{Scalar comparison task}

Participants viewed 2 images representing a difference in scale and were asked to answer a "yes" or "no" question based on the relative size or shape of the two images. The question was presented both on screen and read aloud. Participants also saw a "yes" and "no" on screen and were instructed to select the correct response to the question. In the example below, there is an image of a short worm and a long rope, and the question asks, "Is the worm shorter than the rope?" Therefore, the correct response was to select "yes."

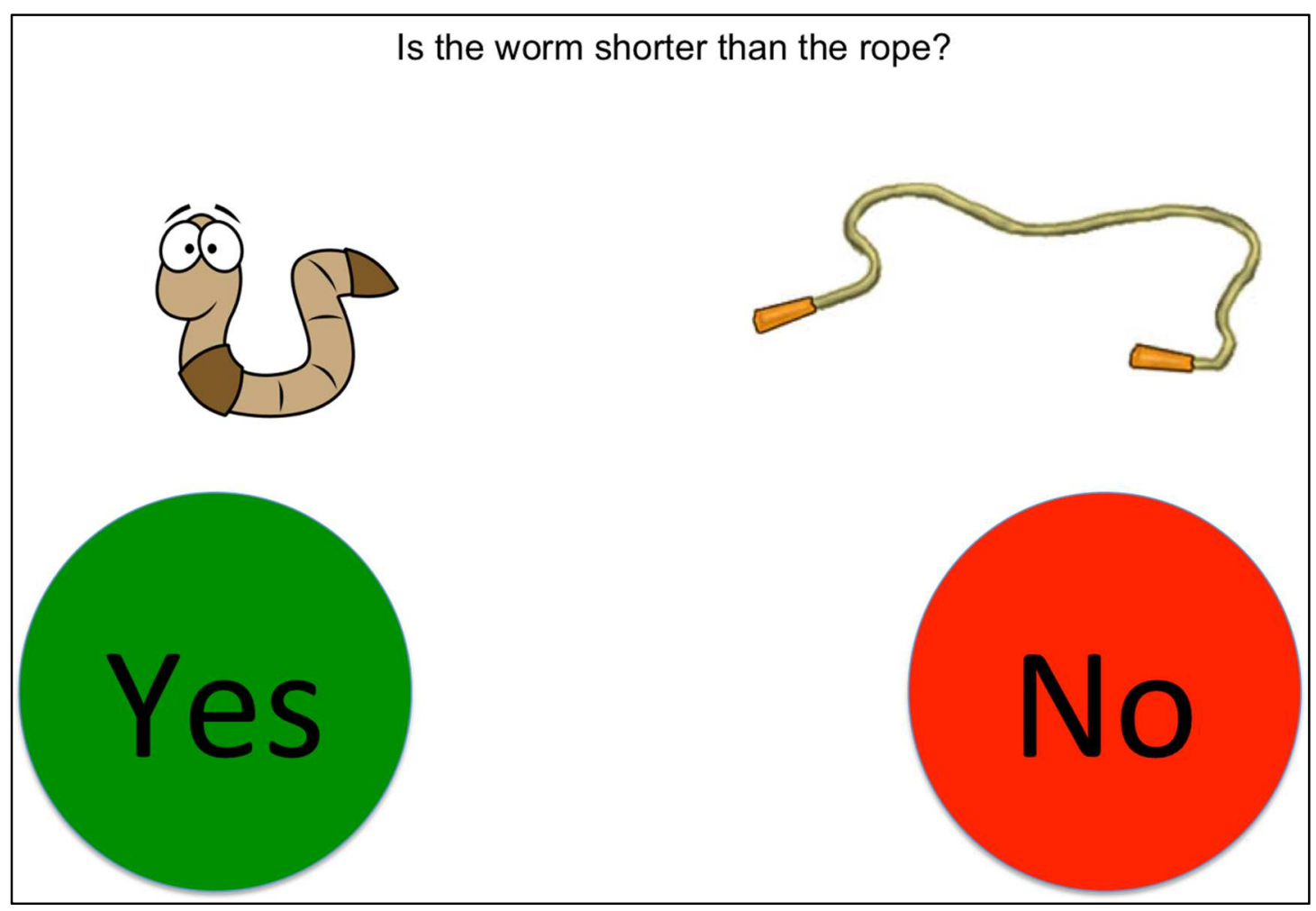




\section{Story recognition memory task}

Participants first listened to a short story with familiar vocabulary. The story was embedded with specific cues to attend to and remember key target words. The story was only spoken, not presented visually, and said, "I woke up this morning. Remember 'morning.' I felt something lick my nose. Remember 'nose.' It was my cat. Remember 'cat.' I put on my glasses. Remember 'glasses.' I looked at my clock. Remember 'clock.' I was late for school. Remember 'school.' I brushed my teeth. Remember 'teeth.' I grabbed my books. Remember 'books.' I ran out the door. Remember 'door.' I was just in time to make the bus. Remember 'bus.' Then, I realized I was wearing my pajamas. Remember 'pajamas."” After hearing the story one time, participants viewed sets of 2 images, one of the target word and one of a reasonable foil, presented in the same sequence as in the original story. In the example below, there is a picture of a cat and a dog. The target word from the story was "cat" from "It was my cat." Therefore, the correct response was to select the cat.
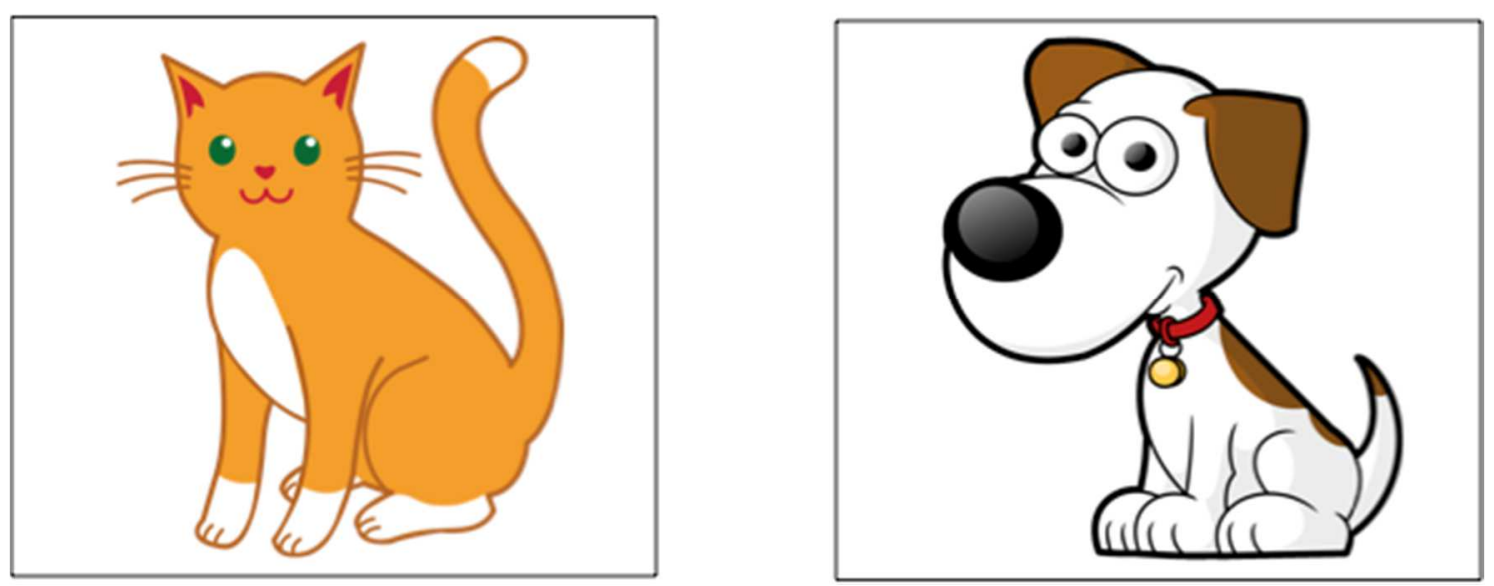


\section{Phonological working memory task}

Participants listened to two spoken strings of syllables. For example, they may hear "BaSee-Da" and "Ba-Kee-Da." Strings of syllables could be between 3 and 8 syllables in length and were each spoken one time. Between the first string and the second string, a two second duration of white noise was included to prevent acoustic memory. Participants saw a smiling face and a frowning face on screen and were instructed to select the smiling face when they believed the two strings were the same and the frowning face when the two strings were different. In the example described here, "BaSee-Da" and "Ba-Kee-Da" differ in the second syllable. Therefore, the correct response was to select the frowning face.

\section{Grammaticality judgment task}

Participants were told that they needed to help a dinosaur learn English by identifying when the dinosaur's speech contained an error. Participants then listened to two a sentence either containing an error or not. For example, they heard "Peter and Sarah is ready to paint." Participants saw a smiling face and a frowning face on screen and were instructed to select the smiling face when they believed the sentence was correct and the frowning face when they heard an error. In the example described here, this sentence contains an error in verb agreement. Therefore, the correct response was to select the frowning face. 


\section{Auditory attention task}

Participants were told that an eagle and a tiger both were receiving instructions and the participant needed to help the tiger, but not the eagle, reach the correct target among a set of 4 possibilities. Instructions for the tiger and the eagle were spoken simultaneously, such that the participant had to segregate and attend to only the tiger's instruction to select the correct target. For example, the participant could hear "Ready Tiger go to red two now" and "Ready Eagle go to blue one now" spoken simultaneously and, viewing the matrix below, would have to select the correct response for the tiger. Therefore, the correct response was to select the red two in the bottom left.
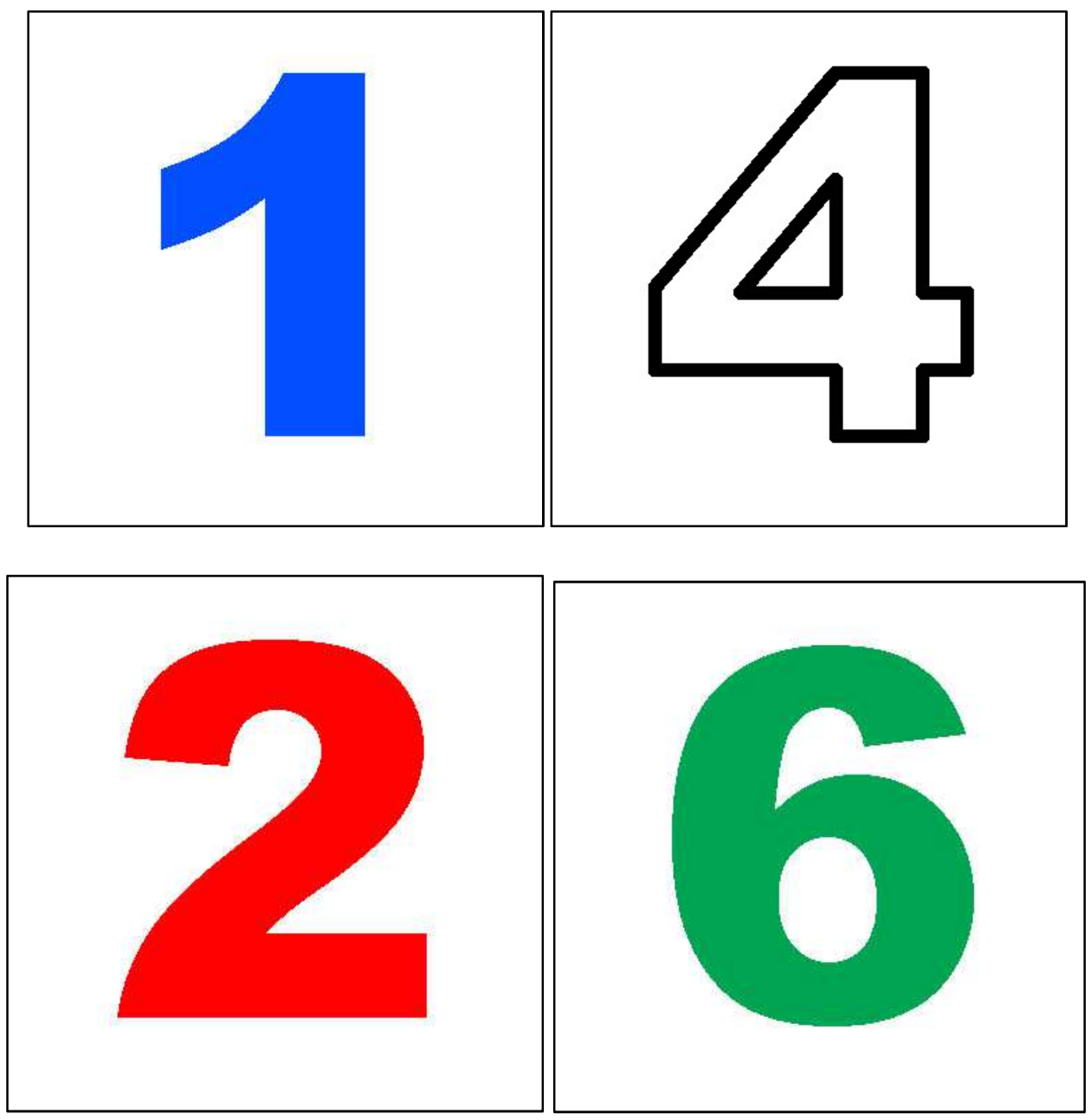


\section{Bibliography}

Anderson, V. A., \& Moore, C. (1995). Age at injury as a predictor of outcome following pediatric head injury: A longitudinal perspective. Child Neuropsychology, 1(3), 187-202.

Asarnow, R. F., Satz, P., Light, R., Lewis, R., \& Neumann, E. (1991). Behavior problems and adaptive functioning in children with mild and severe closed head injury. Journal of Pediatric Psychology, 16(5), 543-555.

Asarnow, R. F., Satz, P., Light, R., Zaucha, K., Lewis, R., \& McCleary, C. (1995). The UCLA study of mild closed head injury in children and adolescents. In S. Broman \& M. E. Michel (Eds.), Traumatic Head Injury in Children and Adolescents. (pp. 117-146). New York: Oxford University Press.

Babikian, T., \& Asarnow, R. (2009). Neurocognitive outcomes and recovery after pediatric TBI: meta-analytic review of the literature. Neuropsychology, 23(3), 283.

Baillargeon, A., Lassonde, M., Leclerc, S., \& Ellemberg, D. (2012). Neuropsychological and neurophysiological assessment of sport concussion in children, adolescents and adults. Brain Injury, 26(3), 211-220.

Barnes, M. A., Dennis, M., \& Wilkinson, M. (1999). Reading after closed head injury in childhood: Effects on accuracy, fluency, and comprehension. Developmental Neuropsychology, 15(1), 1-24.

Beauchamp, M. H., \& Anderson, V. (2010). SOCIAL: an integrative framework for the development of social skills. Psychological Bulletin, 136(1), 39.

Belanger, H. G., \& Vanderploeg, R. D. (2005). The neuropsychological impact of sportsrelated concussion: a meta-analysis. Journal of the International Neuropsychological Society, 11(04), 345-357.

Bergemalm, P.-O., \& Lyxell, B. (2005). Appearances are deceptive? long-term cognitive and central auditory sequelae from closed head injuryi Las apariencias engañan? Secuelas cognitivas y auditivas centrales a largo plazo después de un traumatismo cráneo-encefálico cerrado. International Journal of Audiology, 44(1), 39-49.

Bernstein, D. M. (2002). Information processing difficulty long after self-reported concussion. Journal of the International Neuropsychological Society, 8(5), 673682.

Biddle, K. R., McCabe, A., \& Bliss, L. S. (1996). Narrative skills following traumatic brain injury in children and adults. Journal of Communication Disorders, 29(6), 447-469.

Bijur, P. E., Haslum, M., \& Golding, J. (1990). Cognitive and behavioral sequelae of mild head injury in children. Pediatrics, 86(3), 337-344.

Blanchet, S., Paradis-Giroux, A.-A., Pépin, M., \& Mckerral, M. (2009). Impact of divided attention during verbal learning in young adults following mild traumatic brain injury. Brain Injury, 23(2), 111-122.

Boll, T. J. (1983). Minor head injury in children - out of sight but not out of mind. Journal of Clinical Child \& Adolescent Psychology, 12(1), 74-80.

Bonnier, C., Marique, P., Van Hout, A., \& Potelle, D. (2007). Neurodevelopmental outcome after severe traumatic brain injury in very young children: Role for 
subcortical lesions. Journal of Child Neurology, 22(5), 519-529.

doi: $10.1177 / 0883073807302604$

Borgaro, S. R., Prigatano, G. P., Kwasnica, C., \& Rexer, J. L. (2003). Cognitive and affective sequelae in complicated and uncomplicated mild traumatic brain injury. Brain Injury, 17(3), 189-198.

Brungart, D. S. (2001). Informational and energetic masking effects in the perception of two simultaneous talkers. The Journal of the acoustical society of America, 109(3), 1101-1109.

Brungart, D. S., Simpson, B. D., Ericson, M. A., \& Scott, K. R. (2001). Informational and energetic masking effects in the perception of multiple simultaneous talkers. The Journal of the acoustical society of America, 110(5), 2527-2538.

Carroll, L. J., Cassidy, J. D., Peloso, P. M., Borg, J., von Holst, H., Holm, L., . . W.H.O. Collaborating Centre Task Force on Mild Traumatic Brain Injury. (2004). Prognosis for mild traumatic brain injury: results of the WHO Collaborating Centre Task Force on Mild Traumatic Brain Injury. J Rehabil Med, Suppl.(43 Suppl), 84-105.

Chall, J. S. (1983). Literacy: Trends and explanations. Educational Researcher, 12(9), 38.

Chapman, S. B., Culhane, K. A., Levin, H. S., Harward, H., Mendelsohn, D., EwingCobbs, L., . . Bruce, D. (1992). Narrative discourse after closed head injury in children and adolescents. Brain and Language, 43(1), 42-65.

Cockrell, J. L., \& Gregory, S. A. (1992). Audiological deficits in brain-injured children and adolescents. Brain Injury, 6(3), 261-266.

Collins, M., Lovell, M. R., Iverson, G. L., Ide, T., \& Maroon, J. (2006). Examining concussion rates and return to play in high school football players wearing newer helmet technology: a three-year prospective cohort study. Neurosurgery, 58(2), 275-286.

Davis, G. A., \& Purcell, L. K. (2014). The evaluation and management of acute concussion differs in young children. British Journal of Sports Medicine, 48(2), 98-101.

Dennis, M., \& Barnes, M. A. (1990). Knowing the meaning, getting the point, bridging the gap, and carrying the message: Aspects of discourse following closed head injury in childhood and adolescence. Brain and Language, 39(3), 428-446.

Dennis, M., \& Barnes, M. A. (2000). Speech acts after mild or severe childhood head injury. Aphasiology, 14(4), 391-405.

Ewing-Cobbs, L., \& Barnes, M. A. (2002). Linguistic outcomes following traumatic brain injury in children. Seminars in Pediatric Neurology, 9(3), 209-217.

Ewing-Cobbs, L., Brookshire, B., Scott, M. A., \& Fletcher, J. M. (1998). Children's narratives following traumatic brain injury: Linguistic structure, cohesion, and thematic recall. Brain and Language, 61(3), 395-419.

Ewing-Cobbs, L., Levin, H. S., Eisenberg, H. M., \& Fletcher, J. M. (1987). Language functions following closed-head injury in children and adolescents. Journal of Clinical and Experimental Neuropsychology, 9(5), 575-592.

Field, M., Collins, M. W., Lovell, M. R., \& Maroon, J. (2003). Does age play a role in recovery from sports-related concussion? A comparison of high school and collegiate athletes. The Journal of pediatrics, 142(5), 546-553. 
Gilchrist, J., Thomas, K., Xu, L., McGuire, L., \& Coronado, V. (2011). Nonfatal sports and recreation related traumatic brain injuries among children and adolescents treated in emergency departments in the United States, 2001-2009. Morbidity and Mortality Weekly Report, 60(39), 1337-1342.

Guskiewicz, K. M., \& McLeod, T. C. V. (2011). Pediatric sports-related concussion. $P M \& R, 3(4), 353-364$.

Halstead, M. E., Brown, B. E., \& McAvoy, K. (2017). Cognitive rest following concussions: rethinking 'cognitive rest'. British Journal of Sports Medicine, $51(3), 147$.

Haut, M. W., Petros, T. V., Frank, R. G., \& Haut, J. S. (1991). Speed of processing within semantic memory following severe closed head injury. Brain and Cognition, 17(1), 31-41.

Howell, D., Osternig, L., Van Donkelaar, P., Mayr, U., \& Chou, L.-S. (2013). Effects of concussion on attention and executive function in adolescents. Medicine \& Science in Sports \& Exercise, 45(6), 1030-1037.

Jordan, F. M., Murdoch, B. E., \& Buttsworth, D. L. (1991). Closed-head-injured children's performance on narrative tasks. Journal of Speech, Language, and Hearing Research, 34(3), 572-582.

King, K. A., Hough, M. S., Walker, M. M., Rastatter, M., \& Holbert, D. (2006). Mild traumatic brain injury: Effects on naming in word retrieval and discourse. Brain Injury, 20(7), 725-732.

Kraus, J. F., Fife, D., Cox, P., Ramstein, K., \& Conroy, C. (1986). Incidence, severity, and external causes of pediatric brain injury. American Journal of Diseases of Children, 140(7), 687-693.

Kraus, N., Lindley, T., Colegrove, D., Krizman, J., Otto-Meyer, S., Thompson, E. C., \& White-Schwoch, T. (2017). The neural legacy of a single concussion. Neuroscience Letters, 646, 21-23.

Kraus, N., Thompson, E. C., Krizman, J., Cook, K., White-Schwoch, T., \& LaBella, C. R. (2016). Auditory biological marker of concussion in children. Scientific reports, 6, 39009.

Kriel, R. L., Krach, L. E., \& Panser, L. A. (1989). Closed head injury: Comparison of children younger and older than 6 years of age. Pediatric neurology, 5(5), 296300 .

Lloyd, J., Wilson, M. L., Tenovuo, O., \& Saarijärvi, S. (2015). Outcomes from mild and moderate traumatic brain injuries among children and adolescents: A systematic review of studies from 2008-2013. Brain Injury, 29(5), 539-549.

MacCallum, R. C., Widaman, K. F., Zhang, S., \& Hong, S. (1999). Sample size in factor analysis. Psychological Methods, 4(1), 84.

MacWhinney, B. (1991). The CHILDES project: Tools for analyzing talk: Lawrence Erlbaum Associates, Inc.

Martin, A. W., \& Wiechers, J. E. (1954). Raven's colored progressive matrices and the Wechsler intelligence scale for children. Journal of Consulting Psychology, 18(2), 143.

Mayer, A. R., Yang, Z., Yeo, R. A., Pena, A., Ling, J. M., Mannell, M. V., . . Mojtahed, K. (2012). A functional MRI study of multimodal selective attention following mild traumatic brain injury. Brain imaging and behavior, 6(2), 343-354. 
McKee, A. C., Cantu, R. C., Nowinski, C. J., Hedley-Whyte, E. T., Gavett, B. E., Budson, A. E., . . . Stern, R. A. (2009). Chronic traumatic encephalopathy in athletes: progressive tauopathy following repetitive head injury. Journal of neuropathology and experimental neurology, 68(7), 709.

Merkel, D. L. (2013). Youth sport: Positive and negative impact on young athletes. Open Access J Sports Med, 4, 151-160.

Miller, J., \& Chapman, R. (1985). Systematic analysis of language transcripts. Madison, WI: Language Analysis Laboratory.

Moore, D. R., Pindus, D. M., Raine, L. B., Drollette, E. S., Scudder, M. R., Ellemberg, D., \& Hillman, C. H. (2016). The persistent influence of concussion on attention, executive control and neuroelectric function in preadolescent children.

International Journal of Psychophysiology, 99, 85-95.

Mundfrom, D. J., Shaw, D. G., \& Ke, T. L. (2005). Minimum sample size recommendations for conducting factor analyses. International Journal of Testing, 5(2), 159-168.

Musiek, F. E., Baran, J. A., \& Shinn, J. (2004). Assessment and remediation of an auditory processing disorder associated with head trauma. Journal of the American Academy of Audiology, 15(2), 117-132.

Ponsford, J., Willmott, C., Rothwell, A., Cameron, P., Ayton, G., Nelms, R., .. . Ng, K. (1999). Cognitive and behavioral outcome following mild traumatic head injury in children. The Journal of head trauma rehabilitation, 14(4), 360-372.

Ponsford, J., Willmott, C., Rothwell, A., Cameron, P., Ayton, G., Nelms, R., .. . Ng, K. (2001). Impact of early intervention on outcome after mild traumatic brain injury in children. Pediatrics, 108(6), 1297-1303.

Raven, J. C. (2000). The Raven's progressive matrices: Change and stability over culture and time. Cognitive Psychology, 41(1), 1-48.

Raven, J. C., Raven, J. E., \& Court, J. H. (1956). Coloured progressive matrices: sets A, $A B, B$ : Oxford Psychologist Press.

Rogers, J. M., Fox, A. M., \& Donnelly, J. (2015). Impaired practice effects following mild traumatic brain injury: an event-related potential investigation. Brain Injury, 29(3), 343-351.

Sacco, K., Angeleri, R., Bosco, F. M., Colle, L., Mate, D., \& Bara, B. G. (2008). Assessment Battery for Communication-ABaCo: A new instrument for the evaluation of pragmatic abilities. Journal of Cognitive Science, 9, 111-157.

Satz, P., Zaucha, K., McCleary, C., \& Light, R. (1997). Mild head injury in children and adolescents: A review of studies (1970-1995). Psychological Bulletin, 122(2), 107.

Schechter, J., Araujo, G., \& Dodd, J. (2015). B-99Failed Effort Testing, Post-Concussion Symptoms, and Number of School Days Missed following Pediatric Mild Traumatic Brain Injury. Archives of Clinical Neuropsychology, 30(6), 559-560.

Shaffer, D., Bijur, P., Oliver, F., \& Rutter, M. L. (1980). Head injury and later reading disability. Journal of the American Academy of Child Psychiatry, 19(4), 592-610.

Snodgrass, C., \& Knott, F. (2006). Theory of mind in children with traumatic brain injury. Brain Injury, 20(8), 825-833.

Stablum, F., Mogentale, C., \& Umiltà, C. (1996). Executive functioning following mild closed head injury. Cortex, 32(2), 261-278. 
Tromp, E., \& Mulder, T. (1991). Slowness of information processing after traumatic head injury. Journal of Clinical and Experimental Neuropsychology, 13(6), 821-830.

Turgeon, C., Champoux, F., Lepore, F., Leclerc, S., \& Ellemberg, D. (2011). Auditory processing after sport-related concussions. Ear and Hearing, 32(5), 667-670.

Turkstra, L. S., Dixon, T. M., \& Baker, K. K. (2004). Theory of mind and social beliefs in adolescents with traumatic brain injury. NeuroRehabilitation, 19(3), 245-256.

Uryu, K., Laurer, H., McIntosh, T., Praticò, D., Martinez, D., Leight, S., . . . Trojanowski, J. Q. (2002). Repetitive mild brain trauma accelerates $A \beta$ deposition, lipid peroxidation, and cognitive impairment in a transgenic mouse model of Alzheimer amyloidosis. The Journal of neuroscience, 22(2), 446-454.

Vander Werff, K. R., \& Rieger, B. (2017). Brainstem evoked potential indices of subcortical auditory processing after mild traumatic brain injury. Ear and Hearing, 38(4), e200-e214.

Walz, N. C., Yeates, K. O., Taylor, H. G., Stancin, T., \& Wade, S. L. (2009). First-order theory of mind skills shortly after traumatic brain injury in 3- to 5-year-old children. Dev Neuropsychol, 34(4), 507-519. doi:10.1080/87565640902964490

Wrightson, P., McGinn, V., \& Gronwall, D. (1995). Mild head injury in preschool children: Evidence that it can be associated with a persisting cognitive defect. Journal of Neurology, Neurosurgery \& Psychiatry, 59(4), 375-380.

Ylvisaker, M. (1986). Language and communication disorders following pediatric head injury. The Journal of head trauma rehabilitation, 1(4), 48-56. 